IZA DP No. 10134

Social Norms and Teenage Smoking:

The Dark Side of Gender Equality

Núria Rodríguez-Planas

Anna Sanz-de-Galdeano

August 2016

Forschungsinstitut zur Zukunft der Arbeit Institute for the Study of Labor 


\title{
Social Norms and Teenage Smoking: The Dark Side of Gender Equality
}

\author{
Núria Rodríguez-Planas \\ Queens College, City University of New York \\ and IZA \\ Anna Sanz-de-Galdeano \\ University of Alicante \\ CRES-UPF, MOVE and IZA
}

Discussion Paper No. 10134

August 2016

IZA
P.O. Box 7240
53072 Bonn
Germany

Phone: +49-228-3894-0

Fax: +49-228-3894-180

E-mail: iza@iza.org

Any opinions expressed here are those of the author(s) and not those of IZA. Research published in this series may include views on policy, but the institute itself takes no institutional policy positions. The IZA research network is committed to the IZA Guiding Principles of Research Integrity.

The Institute for the Study of Labor (IZA) in Bonn is a local and virtual international research center and a place of communication between science, politics and business. IZA is an independent nonprofit organization supported by Deutsche Post Foundation. The center is associated with the University of Bonn and offers a stimulating research environment through its international network, workshops and conferences, data service, project support, research visits and doctoral program. IZA engages in (i) original and internationally competitive research in all fields of labor economics, (ii) development of policy concepts, and (iii) dissemination of research results and concepts to the interested public.

IZA Discussion Papers often represent preliminary work and are circulated to encourage discussion. Citation of such a paper should account for its provisional character. A revised version may be available directly from the author. 


\section{ABSTRACT}

\section{Social Norms and Teenage Smoking: The Dark Side of Gender Equality*}

This paper is the first to provide evidence that cultural attitudes towards gender equality affect behaviors with potentially devastating health consequences, and that they do so differently for male and female teenagers. In particular, we show that descending from more gender-equal societies makes girls relatively more prone to smoke than boys. Using data from over 6,000 second-generation immigrant teenagers coming from 45 different countries of ancestry and living in Spain, we find that the higher the degree of gender equality in the country of ancestry, the higher the likelihood that immigrant girls smoke relative to boys, even after we control for parental, sibling, and peer smoking. Importantly, we uncover similar patterns when analyzing other risky behaviors such as drinking or smoking marijuana. This reinforces the idea that more gender-equal social norms may come at an extra cost to women's health, as they increasingly engage in risky behaviors (beyond smoking) traditionally more prevalent among men.

JEL Classification: I10, I12, J15, J16, Z13

Keywords: culture and institutions, smoking, risky behaviors, gender equality, gender gap index

Corresponding author:

Núria Rodríguez-Planas

Economics Department

CUNY Queens College

306-G Powdermaker Hall

65-30 Kissena Blvd.

Queens, NY 11367

USA

E-mail: nuria.rodriguezplanas@qc.cuny.edu

\footnotetext{
* The authors would like to thank Pilar Martínez Alonso, Publication Services Manager from the "Delegación del Gobierno para el Plan Nacional sobre Drogas" in Spain, for kindly allowing us access to the data. We would also like to thank Antonio Cabrales, David Jaeger, Fred Pampel, Joana Tyrowicz, and Wim Vijverberg for comments that helped us improve the paper, as well as comments from participants of the CUNY Applied Economics Seminar in New York, and GRAPE Gender Gaps Conference in Varsaw. Anna Sanz-de-Galdeano acknowledges financial support from the Spanish Ministry of Economy and Competitiveness Grant ECO2014-58434-P.
} 


\section{Introduction}

Although smoking is more prevalent among men, women in many countries are catching up, raising concerns of a future epidemic of tobacco use among women. According to the World Health Organization, about 200,000 million of the 1 billion smokers are women (WHO, 2010). The female-to-male smoking prevalence ratio varies widely across countries (Guindon and Boisclair, 2003; and Payne, 2005). In high-income countries, women smoke as much as men (WHO, 2008). In contrast, in low- and middle-income countries, women smoke much less than their male counterparts. However, women's smoking prevalence rates are expected to rise faster than those of men. The reason is that more than three quarters of smokers begin smoking before their $19^{\text {th }}$ birthday (Gruber, 2001b), and smoking take-up rates among girls and boys around the world are converging (Warren et al., 2006) and, in some countries, girls already smoke more than boys (such as, in Bulgaria or Spain). ${ }^{1}$ According to Mackay and Amos (2003), the smoking rate among women around the world is estimated to rise to 20 percent by 2025 (up from 9 percent in 2010), while that of men is estimated to decrease. With 5 million people dying every year from tobacco use (1.5 of which are women), the rising epidemic of tobacco use among women begs for a better understanding of the gender differences in smoking as urgent action is needed to prevent tobacco from killing up to 2.5 million women by 2030 (WHO, 2010). The issue is particular pressing among adolescents as youth smoking causes smoking later in life (Gruber, 2001a). ${ }^{2}$

While many studies analyze the determinants of smoking and the effects of tobacco control policies, ${ }^{3}$ the research aiming to explain gender differences in smoking is scarcer and focuses on adult or young adult populations (as opposed to adolescents). ${ }^{4}$ To the best of our knowledge two studies focus on the gender

\footnotetext{
${ }^{1}$ See Baska et al. (2009) for Bulgaria, and current paper for Spain.

${ }^{2}$ Importantly, studies based on more recent data have confirmed that previous smoking behavior is a relevant causal contributor to smoking persistence even after accounting for individual observed and unobserved heterogeneity both among teenagers (Gilleskie and Strumpf, 2005) and among adults (Christelis and Sanz-de-Galdeano, 2011).

3 See, for example, Chaloupka and Wechsler (1997), Gruber and Zinman (2000), Gruber (2001b), Colman, Grossman and Joyce (2003), Adda and Cornaglia (2006, 2010) and the references therein.

${ }^{4}$ The literature has focused on describing gender adult differential prevalence in smoking around the world (Ezzati and Lopez, 2003; WHO, 1992). Branstetter et al. (2012) are among the few
} 
differential determinants of adult smoking using individual data (Bauer et al., 2007; and Chung et al., 2010). Both studies find that most gender smoking differences are due to gender behavioral differences (Bauer et al., 2007) or differences in "inclination to smoke” (Chung et al., 2010), as opposed to gender differences in socio-demographic characteristics. ${ }^{5}$ Most aggregate-data studies have focused on identifying which factors are associated with cross-country variation of the female-to-male smoking ratio (Pampel, 2001 and 2006; Shaap et al., 2009; Hitchman and Fong, 2011; French et al., 2013). ${ }^{6}$ Nonetheless, all of these studies capture correlations, rather than causal inference. Moreover, aggregate-data studies focus on the effects of variation in formal institutional constraints, such as the countries' labor market institutions, use of excise taxation, smoking restrictions (including those on youth), clean-air regulations, cigarettes' prices and production; ${ }^{7}$ as opposed to the effects of differences in informal institutional constraints or culture, ${ }^{8}$ defined as "beliefs and preferences that vary systematically across groups of individuals separated by space (either geographic or social) or time” (Fernández, 2008). The objective of the current paper is to understand the role of informal institutional constraints (culture or social norms) apart from environmental factors (or formal economic and institutional constraints) in explaining gender differences in smoking among adolescents.

While others have found that culture affects economic behavior, this paper is the first to provide evidence that cultural attitudes towards gender equality affect behaviors with potentially devastating health

exploring gender differences in smoking and cessation among teenagers using a sample of 755 adolescents in the US.

${ }^{5}$ Bauer et al. (2007) use a German survey containing over 20,000 individuals in 1998, 2002, and 2004, while Chung et al. (2010) focus on a cross-sectional survey with over 15,000 Koreans in 2001 and 2005.

${ }^{6}$ While Hitchman and Fong (2011) find that gender political empowerment is correlated with the gender smoking ratio, earlier cross-sectional studies did not find evidence that greater gender equality reduced the smoking gender gap (Pampel, 2001, 2006; and Shaap et al., 2009).

${ }^{7}$ A related literature using individual data examines gender differences in response to antismoking policies (Townsend et al., 1994; and Chaloupka and Paccula 1999), or gender differences to price or income elasticities (Townsend et al., 1994; and Chaloupka and Paccula 1999; Hersch 2000; and Yen, 2005).

${ }^{8}$ Note that there is no commonly agreed upon definition of culture. See Fernández $(2008,2011)$ and the references therein for a more detailed discussion of the meaning of culture in the context of the literature on economics and culture. 
consequences, and that they do so differently for male and female teenagers. ${ }^{9}$ In particular, we show that descending from more gender-equal societies makes girls relatively more prone than boys to smoke and engage in other risky behaviors such as drinking or smoking marijuana. We also provide evidence of the mechanisms behind the transmission of culture, namely mothers' (lack of) human capital, easy access to cigarettes, and parental monitoring.

For the sake of exposition, suppose that culture did not matter and that only formal institutions were relevant in shaping behavior. In that case, girls would choose to smoke more (or less) than boys (regardless of beliefs) because they may be systematically targeted by pro-smoking advertising campaigns (National Cancer Institute, 2008; WHO 2009; and Choudhury et al., 2010) and cigarette designs that ease the transition from experimentation to established use (Cummings et al., 2002), or systematically ignored by information campaigns about the harms of tobacco products; ${ }^{10}$ or they may have less disposable income than boys or they may not be part of the dominant social group and, hence, they would have less access to a costly, scarce, or technologically innovative good, such as cigarettes. ${ }^{11,12}$

\footnotetext{
${ }^{9}$ Other authors have used a similar approach to estimate the effects of culture on different socioeconomic outcomes, including savings rates (Carroll, Rhee, and Rhee 1994); stock market participation (Osili and Paulson, 2008); preferences for redistribution (Luttmer and Singhal, 2011); fertility and female labor force participation (Antecol 2000; Fernández and Fogli 2006, 2009; Fernández 2007); living arrangements (Giuliano 2007), the demand for social insurance (Eugster et al. 2011); preferences for a child's sex (Almond, Edlund, and Milligan 2013); divorce (Furtado, Marcén, and Sevilla 2013); and math test scores (Nollenberger, Rodríguez-Planas, and Sevilla, 2016). Using a complementary approach that exploits temporal and inter-generational variation, Christopoulou and Lillard (2015) find that culture affects the smoking behavior of British immigrants' descendants living in Australia and the US. Using an alternative approach, Polavieja (2015) also explores the effect of culture on fertility by imputing traits from the nonmigrant population of the country of origin to the migrant population. To the best of our knowledge, no one has studied whether culture explains gender differences in smoking.

${ }^{10}$ The WHO explains that tobacco advertising increasingly targets girls. The theme for World No Tobacco day in 2010 was "Gender and Tobacco with an emphasis on marketing to women", according to Haglund (2010).

${ }^{11}$ See Gruber and Zinman (2000) for a literature review on youth smoking responsiveness to prices of cigarettes.

${ }^{12}$ The literature on the diffusion of innovations establishes that the high-status persons adopt the innovative product earlier (Rogers, 1995; and Strand and Soule 1998). Ferrence (1989) shows that the diffusion of manufactured cigarettes has followed this status-based diffusion pattern. To the extent that women are the less dominant group (relative to men), their adoption of cigarette smoking follows that of men. While the diffusion hypothesis needs a minimum threshold of female independence for the widespread adoption of cigarette smoking to begin, it does not need change in gender equality to explain the declining sex difference in smoking patterns. Instead, the decline in the gender smoking gap is one of the stages of the diffusion of cigarette use (Pampel, 2003).
} 
Alternatively, if only culture mattered, girls’ higher (or lower) smoking would be the result of having internalized certain beliefs and values related to gender identity, which may affect: (1) a girl's beliefs on smoking-while in modern societies these beliefs may be of the type: “as I am a girl, smoking makes me liberated, carefree, modern, unconventional, emancipated, or independent"; ${ }^{13}$ in more traditional societies, it may be the opposite: "as I am a girl, smoking makes me inappropriate or unfeminine"; ${ }^{14}$ (2) a girl's beliefs on the institutional constraints she may face-_"as I am a girl, smoking will make others perceive me as more male-like and hence confident, assertive, professional, and successful in the labor market; or more glamorous, sophisticated, sociable, attractive, or slim, and, hence, more attractive in the marriage market”; or (3) a girl's beliefs on the stage in the diffusion of innovation (cigarettes, in this case) or the smoking epidemic she is in-which is not the actual stage in the host country, but that of her parents' country of ancestry- “as I am a girl, my parents' beliefs on the stage of the diffusion of cigarettes or the epidemic they are in will make it easier for me to smoke either because I have easier access to cigarettes or because my parents are more lenient and give me more freedom to engage in smoking”. ${ }^{15}$

Evidence that institutions matter would suggest that health authorities ought to become increasingly sensitive to gender when formulating and implementing tobacco control policies by, for instance, making sure marketing strategies do not target girls. Alternatively, evidence that culture matters would suggest that gender-tailored smoking reduction and cessation interventions need to account for differences in gender social norms, and possibly consider modifying them directly. Crucially, understanding the role of informal institutional constraints is fundamental to guide policy making on modifying formal institutions (as explained by North, 1990).

\footnotetext{
${ }^{13}$ See Nathanson (1995) and Waldron (1991) for examples of such type of arguments.

${ }^{14}$ As explained by Kaplan et al. (1990); Waldron et al. (1988) in their ethnographic studies. See also Waldron (1991).

${ }^{15}$ Note that even if expected institutional constraints are driven by actual constraints in the country of ancestry, it is still a story about beliefs. Alternatively, even if the smoking epidemic or diffusion hypothesis holds in the country of ancestry, findings from second-generation immigrants would still be a story about beliefs.
} 
We analyze the smoking behavior of over 6,000 second-generation immigrant 15- to 18-year old girls and boys coming from 45 different countries of ancestry and living in Spain. ${ }^{16}$ By focusing on second-generation immigrants living in the same host country, we are holding constant the host country's formal institutions (namely, economic institutions, rules and regulations regarding tobacco use, distribution, and advertisement, as well as the costs and taxes of tobacco products or the stage in the diffusion of cigarette the host country is in). ${ }^{17}$ Thus, if only current formal institutional constraints or the stage in the epidemic or diffusion of cigarette in the host country determine gender differences in smoking, country-of-ancestry gender differences in smoking prevalence should not matter, after controlling for individuals' sociodemographic and family characteristics. Evidence that country-of-ancestry female-to-male smoking prevalence ratio affects second-generation-immigrant girls' host-country likelihood of smoking relative to that of their male counterparts would provide strong evidence that cultural values (such as social norms and customs regarding gender smoking habits) affect the smoking gender gap.

We merge data from a nationally representative cross-sectional survey of substance abuse among high-school students in Spain in 2006, 2008, 2010 and 2012 (Encuesta Estatal sobre Uso de Drogas en Enseñanzas Secundarias, ESTUDES hereafter) with country-of-ancestry data from several sources (as explained in the data section), and show that the higher the female-to-male smoking prevalence ratio in the country of ancestry, the higher the likelihood of smoking among second-generation immigrant girls relative to boys in the host country. Our results suggest that social norms regarding gender smoking habits matter in determining second-generation immigrants' smoking likelihood in the host country. More precisely, a one-standard increase in the country-of-ancestry female-to-male smoking prevalence ratio is associated with a 4.6 percentage points higher likelihood of smoking among girls relative to boys in Spain, the equivalent to an 84 percent increase (as, on average, the likelihood of smoking in

\footnotetext{
${ }^{16}$ Second-generation immigrants are individuals born in country they live in to parents (at least one of them) born in a different country.

${ }^{17}$ We call Spain the "host" country because it is the host country their parents immigrated to.
} 
Spain among second-generation girls is 5.5 percentage points higher than that of boys). This estimate is statistically significant at the 1 percent level.

We then estimate whether cultural attitudes towards gender equality matter in determining second-generation immigrants' gender smoking gap in the host country, using the 2010 World Economic Forum's gender gap index (GGI, hereafter), which reflects economic and political opportunities, education and well-being for women in the country of ancestry. ${ }^{18}$ We find strong evidence that social norms regarding the degree of gender equality in the country of ancestry affect the relative likelihood of smoking of second-generation girls relative to boys in the host country. In particular, we find that a one standard deviation increase in the country of ancestry's GGI is associated with a higher likelihood of smoking among second-generation immigrant girls relative to boys in Spain that ranges between 2.4 and 3.9 percentage points (or between 44 and 71 percent) depending on the specification. This effect is statistically significant at the 1 percent level.

Interestingly, while socio-demographic characteristics, including parents and siblings' tobacco use, may be associated with higher (or lower) likelihood of smoking, only our cultural proxies in the country of ancestry have a gender differential effect on the likelihood of smoking in the host country. Our results are robust to different specification strategies, selective migration, adjustments of standard errors, alternative measures of gender equality, and changes in sample criteria. Most importantly, the effect of gender social norms on the smoking gender gap remains even after we control for a large set of youth and parental characteristics, as well as parental, sibling, and peer smoking. The paper also identifies which country-of-ancestry institutions are behind this transmission of beliefs. Namely, we find that beliefs on women's educational attainment and health and survival matter the most.

Exploring the different mechanisms driving the effect of culture on the smoking gender gap, we find that mothers' lack of human capital mediates in the transmission of beliefs. We also find that while having siblings and peers who

18 The GGI is the same index used by Guiso et al. (2008), Fryer and Levitt (2010), and Nollenberger, Rodríguez-Planas, and Sevilla (2016), which analyze the effect of gender equality on the math gender gap. ${ }^{19}$ Some authors have found evidence of gender differences in acculturation and smoking behavior among first-generation Latinos and Asians in the US (Bethel and Schenker, 2005; Zhang and Wang, 2008; Gorman et al., 2014; and Leigh and Leung, 2014). 
smoke reinforces the effect of culture, gender social norms affect the smoking gender gap even among those whose siblings or peers do not smoke. Interestingly, we find no evidence that maternal employment or family structure affect the transmission of beliefs.

We find that this pattern extends to other risky behaviors, namely drinking alcohol, getting drunk, smoking marijuana or getting into fights, suggesting that the importance of culture expands beyond the decision to smoke. We then explore whether social norms also affect the perceived risks of smoking, the information received on the harms of drugs, or parental supervision. While we find no evidence that girls whose parents come from more gender-equal countries report different perceived risks of smoking or patterns of acquisition of drug-related information relative to boys; they are more likely to have more access to cigarettes, and have less parental supervision in general than their male counterparts. This evidence is suggestive that beliefs are transmitted at least in the following two ways: parental monitoring and easy access to cigarettes, providing support for the hypothesis that beliefs on the stage of the diffusion of cigarettes or the epidemic the girl is in-which is not the actual stage in the host country, but that of her parents' country of ancestry-are being transmitted.

The remainder of this paper is organized as follows. Sections 2 and 3 describe the empirical strategy, the Spanish institutional background and the data. Section 4 presents estimates of the effects of social norms and customs regarding gender smoking habits and gender equality on second-generation immigrant girls' likelihood of smoking relative to that of boys. Section 5 quantifies the effect of culture relative to other well-known determinants affecting youth smoking, and Section 6 presents sensitivity analysis, respectively. Section 7 presents subgroup analysis. Section 8 explores whether social gender norms from the country-of-ancestry also affects other risky behaviors. Section 9 presents results on the effects of culture on gender differences in perceived risk, access to tobacco, information on the risks of drugs, and parental leniency, among others. Section 10 concludes. 


\section{Empirical Strategy}

To examine whether country-of-ancestry social norms affect gender differences in youth smoking, we use a sample of second-generation immigrants aged 15 to 18 to estimate equation (1):

$S_{i j k t}=\alpha_{1}$ female $_{i}+\alpha_{2} G E_{j}+\alpha_{3}\left(\right.$ female $\left._{i} * G E_{j}\right)+X^{\prime}{ }_{i j k t} \beta_{1}+X^{\prime}{ }_{i j k t} *$ female $_{i} \beta_{2}+$ $\lambda_{k}+\lambda_{t}+\varepsilon_{i j k t}$

where $S_{i j k t}$ is the decision to smoke of individual $i$ from country of ancestry $j$, and living in province $k$ in survey year $t$. To identify smoking differences between girls and boys, the variable female $e_{i}$ is an indicator equal to one if the individual is a girl and zero otherwise. $G E_{j}$ is a variable that proxies gender social norms in the country of ancestry $j$. The vector $X_{i j k t}$, includes a set of individual and family characteristics that may affect smoking habits. These individual characteristics are also interacted with the female indicator. $\lambda_{k}$ and $\lambda_{t}$ are a full set of dummies that control for the individual's host-country province of residence $k$, and the year of the survey $t$. Year fixed effects $\left(\lambda_{t}\right)$ account for cohort differences and other time variation. We include province-of-residence fixed effects $\left(\lambda_{k}\right)$ to account for the province's characteristics that may be related to smoking habits. Standard errors are clustered at the country-of-ancestry level, which is the source of identification.

Our coefficient of interest is that of the interaction between $G E_{j}$ and the female indicator, $\alpha_{3}$, which captures the role of country-of-ancestry gender social norms in explaining gender differences in smoking of second-generation immigrant girls and boys in the host country. A positive and significant $\alpha_{3}$ would suggest that more gender equality in the immigrant's country of ancestry is associated with higher smoking among second-generation immigrant girls relative to boys, and thus a smaller smoking gender gap in the host country. Equation (1) has been estimated using OLS and, as a robustness check, we have also used nonlinear models (logit and probit) and subsequently computed average partial effects.

As indicated above, we restrict our sample to second-generation immigrants who were born and reside in the same host country (and therefore, share the same economic and institutional environment) but whose parents were 
born in another country (such that their social beliefs are potentially different). This way of disentangling cultural from environmental factors is at the core of the epidemiological approach which has been thoroughly reviewed by Fernández (2011).

Because second-generation immigrants are born and live in the same area (the host country), using them minimizes their ties with non-immigrating family members, as well as the role of formal institutions in the country of ancestry on second-generation immigrants’ outcomes. However, as Fernández (2011) points out, parents are not the only transmitters of culture, which will lead to an underestimation of the effect of culture in the specification of equation (1). Moreover, to the extent that both our teenagers and our teenagers' parents (who are first-generation immigrants) are acculturated and their beliefs on smoking converge to those of natives in the host country, our estimates of culture will be also be downward biased. ${ }^{19}$

\section{Institutional Background and Data}

\section{Institutional Background}

Tobacco use among women in Spain began in the late 1960s/early 1970s, first among the college educated, and progressively across all education levels and socio-demographic groups. According to the World Bank Database, in the period 2011-2015, as many as 34 percent of Spanish males and 28 percent of Spanish females aged 15 and older smoke. In contrast to the adult population, teenager girls (14 to 18 years old) in Spain are more likely to smoke than their male counterparts. In 2012, 33.1 percent of boys and 37.5 percent of girls aged 14 to 18 years old smoked (Ministerio de Sanidad, 2013).

In Spain, tobacco laws are regulated at the national level and they have been slow to develop. The first tobacco prevention law, passed in 1988, forbade smoking in schools and hospitals. It also set the minimum age to purchase tobacco at 16 years of age. Seventeen years later, on December 26 2005, the law 28/2005 increased the legal age to purchase tobacco to 18 years of age. In

19 Some authors have found evidence of gender differences in acculturation and smoking behavior among first-generation Latinos and Asians in the US (Bethel and Schenker, 2005; Zhang and Wang, 2008; Gorman et al., 2014; and Leigh and Leung, 2014). 
addition, this law also established that all cigarette packages are required to state on the package the minimum legal age to purchase tobacco.

\section{ESTUDES Data}

Our main data set uses the cross-sectional survey of substance abuse among high-school students in Spain (Encuesta Estatal sobre Uso de Drogas en Enseñanzas Secundarias, ESTUDES hereafter). Although the survey is conducted bi-annually since 1994, data are publicly available to researchers starting in 2004. Our analysis focuses on the 2006 to 2012 waves. We excluded the 2004 wave because it does not contain information on parents' country of birth. The 2012 wave is the latest wave available up to date.

The survey asks youths about smoking habits. Our main outcome variable is the decision to smoke, which takes the value one if the individual reported smoking in the past 30 days, and zero otherwise. In addition to smoking habits, ESTUDES also collects further information on the student, his or her family, and peers, including the student's age, the highest educational level achieved and the employment status of his or her mother and father at survey date, and his or her household composition. We also observe whether the student has fallen behind a grade, whether the student works, and the smoking habits of the students' parents, siblings, friends and school-peers. Appendix Table A.1 presents basic descriptive statistics of all ESTUDES variables used in the analyses.

\section{Country-Level Variables}

To proxy gender social norms, we focus on two main country-of-ancestry variables: the female-to-male adult smoking prevalence ratio and the gender gap index (the GGI, hereafter).

The female-to-male adult smoking prevalence ratio is estimated using adult male and female smoking prevalence from the World Bank Indicators (WBI, hereafter). Female (male) smoking prevalence is estimated as the percentage of women (men) aged 15 and over who smoke any form of tobacco, including cigarettes, cigars, pipes or any other smoked tobacco products in 2010. Smoking includes daily, non-daily, or occasional smoking. In addition, for those countries for which this information was not available in the WBI, the male and 
female smoking prevalence was obtained from either Nation Master or from Table 2 in Muller and Wehbe (2008) for different years. ${ }^{20}$

The GGI is collected from the 2010 World Economic Forum report, except for two countries, Belarus and Burundi, for which the GGI comes from the 2009 and 2011 World Economic Forum report, respectively, as they were not available in 2010. The GGI measures the relative position of women in a society taking into account the gap between men and women in four different areas: economic opportunities and participation, educational attainment, political achievements, and health and survival. The highest possible score is 1 (equality) and the lowest possible score is 0 (inequality).

In our analysis, we also estimate the effect of these four separate areas of gender equality on the gender smoking gap in order to identify which formal institutions in the country of ancestry affect inter-generational transmitted beliefs. The economic participation and opportunity index is based on gender differences in salaries, labor-force participation levels, and access to high-skilled employment. The educational attainment index captures gender differentials on access to both basic and higher education levels. The political empowerment index measures gender differences in different outcomes regarding the representation in decision-making structures. The health and survival index reflects gender differences on life-expectancy and sex-ratio outcomes. All of these indices range from 0 to 1 , with larger values indicating a better position of women in society. To simplify comparison of estimates across specifications using alternative measures of gender equality, all of our country-of-ancestry variables are standardized such that they have a mean of 0 and a standard deviation of 1.

Most of our different measures of culture in the country of ancestry are measured contemporaneously instead of at the time parents migrated to Spain (as

\footnotetext{
${ }^{20}$ From Muller and Wehbe (2008), we obtained data from Colombia, Guatemala, Nicaragua, Peru and Venezuela. As explained in the notes of their table, Guatemala and Venezuela data come from PATIOS online database (Organización Panamericana de la Salud 2005); Colombia and Peru data come from the $2^{\text {nd }}$ edition of The Tobacco Atlas of the American Cancer Society (Mackay et al., 2006), Central American Diabetes Initiative (Organización Panamericana de la Salud, 2003); and Nicaragua data come from Central American Diabetes Initiative (Organización Panamericana de la Salud, 2003). From Nation Master (http://www.nationmaster.com/), we obtained data from Algeria (2003), Gambia (1997), and Syria (1999). ${ }^{21}$ In our sample of secondgeneration immigrants, when both their parents come from a foreign country, in about $82 \%$ of the cases they come from the same foreign country.
} 
information on parents' tenure in the host country is unavailable in the survey). Notice that, even if this information were available, the GGI is only available starting in 2006. It is worth highlighting that the use of contemporaneous measures of culture is a common practice in the epidemiological literature (Giuliano, 2007; Fernández and Fogli, 2009; Furtado, Marcen and Sevilla, 2013; and Nollenberger, Rodriguez-Planas, Sevilla, 2016; among others). The argument supporting it is that it is likely that countries' aggregated preferences and beliefs change slowly over time. An alternative and complementary argument claims that parents transmit the social norms of their contemporaneous country-of-origin counterparts.

\section{Sample of Second-Generation Immigrants and Descriptive Statistics}

To implement the empirical strategy described in Section 2, we restrict our ESTUDES sample to second-generation immigrants who were born and reside in Spain but whose parents (at least one of them) were born in another country.

Because identification comes from variation in our measures of parental country-of-origin culture, we pool the 2006, 2009, 2010 and 2012 ESTUDES waves to maximize the number of countries of ancestry. If both parents are immigrants, we assign the mother's country of origin because evidence from Blau et al. (2013) and Christopoulou and Lillard (2015) show that mother's culture is more relevant for girls than father's culture. ${ }^{21}$ If mother's country of origin is unavailable, or she was born in Spain, we use the father's country of origin.

When using the female-to-male smoking prevalence ratio as a proxy for culture, we restrict our sample to those individuals for whom we observe this variable in their country of ancestry. ${ }^{22}$ Analogously, when using the GGI as a proxy for culture, we restrict our sample to those individuals for whom we

\footnotetext{
${ }^{21}$ In our sample of second-generation immigrants, when both their parents come from a foreign country, in about $82 \%$ of the cases they come from the same foreign country.

${ }^{22}$ The lack of female-to-male smoking ratio implies losing the following ancestry territories: Angola, Bermuda, Chad, Democratic Republic of the Congo, Equatorial Guinea, Gabon, Gibraltar, Guinea-Bissau, Guyana, Democratic People's Republic of Korea, Libya, Liechtenstein, Madagascar, Mayotte, Monaco, New Caledonia, West Bank and Gaza, Sao Tome and Principe, Taiwan, Timor-Leste, and Western Sahara.
} 
observe this variable in their country of ancestry. ${ }^{23}$ We also drop secondgeneration immigrants whose country of ancestry has fewer than 10 observations in a given host country. ${ }^{24}$ In the robustness section, we explore the sensitivity of our results to changes in sample selection criteria.

Our final sample has over 6,000 second-generation migrants from 45 different countries of ancestry (as shown in Table 1). Countries of ancestry are from various continents and levels of development. Indeed, the countries of ancestry in our sample cover all continents, with many European (14 countries) and some transition economies (Poland, Romania, and Russia), several countries in America (Bolivia, Canada, Chile, Colombia, Cuba, Dominican Republic, Ecuador, El Salvador, Mexico, Peru, United States, Uruguay, and Venezuela), some in Asia (China, India, Japan, and Philippines), Africa (Algeria, Angola, Gambia, Morocco, Senegal, and South Africa), Middle East (Lebanon, Iran, and Syria) and one country in Oceania (Australia). Countries of ancestry contributing the most to our sample of second-generation immigrants are Morocco, France, Germany and Venezuela (second-generation immigrants whose parents were born in these countries represent 43 percent of the sample). ${ }^{25}$

${ }^{23}$ The lack of gender equality measures implies losing the following ancestry territories: Afghanistan, Andorra, Bermuda, Bosnia and Herzegovina, Burundi, Cabo Verde, Republic of the Congo, Democratic Republic of the Congo, Djibouti, Equatorial Guinea, Gabon, Gibraltar, Guinea, Guinea-Bissau, Haiti, Iraq, Republic of Korea, Democratic People's Republic of Liberia, Libya, Liechtenstein, Mayotte, Monaco, New Caledonia, West Bank and Gaza, Puerto Rico, Sao Tome and Principe, Serbia, Sierra Leone, Taiwan, Timor-Leste, Turkmenistan, and Western Sahara.

${ }^{24}$ This is a common practice in the literature. For instance, Fernández and Fogli (2006) eliminate those countries of ancestry with fewer than 10 observations. Given that our regressions are run at the individual level, whether we include these small numbers of observations does not affect our results. With this adjustment, we lose 159 individuals. ${ }^{25}$ While Moroccans, Ecuadorians and Romanians represented the three largest nationalities of immigrants in Spain at the turn of the century, Ecuadorians and Romanians only began to immigrate to Spain in large numbers after the turn of the century (Rodriguez-Planas and Vegas, 2014). Hence, it is not surprising that we observe fewer second-generation immigrants from these two countries. ${ }^{26}$ This is calculated as [Female to Male Smoking Ratio ${ }_{U S A}(0.786)-$ Female to Male Smoking Ratio Morocco $(0.047)=0.739] / 0.324 * \hat{\alpha}_{3}(0.046)=0.1049$ and $\left[G G I_{U S A}(0.741)-G G I_{\text {Morocco }}(0.577)=0.164\right] / 0.061 * \hat{\alpha}_{3}(0.039)=0.1048 . \quad$ Note that these calculations would not necessarily deliver so similar results in other cases.

${ }^{25}$ While Moroccans, Ecuadorians and Romanians represented the three largest nationalities of immigrants in Spain at the turn of the century, Ecuadorians and Romanians only began to immigrate to Spain in large numbers after the turn of the century (Rodriguez-Planas and Vegas, 2014). Hence, it is not surprising that we observe fewer second-generation immigrants from these two countries. ${ }^{26}$ This is calculated as [Female to Male Smoking Ratio ${ }_{U S A}(0.786)-$ Female to Male Smoking Ratio Morocco $(0.047)=0.739] / 0.324 * \hat{\alpha}_{3}(0.046)=0.1049$ and 
Table 1 presents summary statistics for our sample of second-generation immigrants by country of ancestry. The first column shows smoking differences in Spain between second-generation immigrant girls and boys by country of ancestry, measured as the difference between the average female smoking prevalence (displayed in Column 2) and the average male smoking prevalence (shown in Column 3). Countries of ancestry are ordered by the magnitude of the gender smoking gap in Spain. Column 1 shows a large variation in the gender smoking gap across countries of ancestry. At the top 10 percent of the smoking gender gap distribution by country of ancestry, second-generation immigrant girls smoke more than boys by 28 percentage points. At the bottom 10 percent of the smoking gender-gap distribution, second-generation immigrant girls smoke substantially less than boys by 34 percentage points. On average, the difference in smoking probabilities between girls and boys in our sample is +5.5 percentage points, indicating that second-generation girls are more likely to smoke than their male counterparts in Spain. This gender difference in smoking prevalence, which is statistically significant at the $1 \%$ level, is identical to that of native teens and quite similar to that observed among all youth (including firstand second-generation immigrants and natives) living in Spain (see Appendix Table A.2).

Columns 4 to 9 in Table 1 show the value of different gender-equality measures in each country of ancestry. There is considerable dispersion in the female-to-male smoking prevalence ratio across countries of ancestry as it varies from 96.79 percent in Norway to 1.24 percent in Algeria. The variation in the GGI is also far from negligible, as it ranges from 59.3 percent in Syria to 84.0 percent in Norway. The average female-to-male smoking ratio (GGI) across countries averages 56.88 (68.66) percent with a 32.40 (6.08) percent standard deviation.

Table 2 displays cross-correlations between the gender smoking gap in Spain and the different measures of gender equality in the country of ancestry. The correlation between the gender smoking gap in Spain and the different measures of gender equality in the country of ancestry ranges between 0.074 (for

$\left[G G I_{U S A}(0.741)-G G I_{\text {Morocco }}(0.577)=0.164\right] / 0.061 * \widehat{\alpha}_{3}(0.039)=0.1048 . \quad$ Note that these calculations would not necessarily deliver so similar results in other cases. 
political empowerment) and 0.277 percent (for gender equality regarding educational attainment). Not surprisingly, Table 2 shows that the crosscorrelations between our different country-of-ancestry measures are generally higher; for instance the correlation between the female-to-male smoking prevalence ratio and the GGI is 0.69 , while the correlation between the countryof-ancestry female-to-male smoking prevalence ratio and the different components of the GGI varies from 0.34 for the health and survival index to 0.62 for the educational attainment index.

Figure 1 plots the female-to-male smoking ratio of second-generation immigrants in Spain by country of ancestry versus the (non-standardized) GGI in the country of ancestry. Overall, the raw data show that the more gender equality in the country of ancestry the higher the likelihood that secondgeneration immigrant girls smoke with respect to boys. The regression line has a slope of 3.142 with a standard error of 0.926 . The adjusted $R^{2}$ is 0.20 . Similar results are found when instead of the GGI we use the female-to-male smoking prevalence ratio in the country of ancestry instead as shown in Appendix Figure A.1.

\section{Main Results: Does Culture Affect the Youth Smoking Gender Gap?}

\section{Baseline Findings and Alternative Measures of Culture}

Table 3 displays the estimated coefficient on the interaction between the female indicator and the culture proxy in the country of ancestry, $\hat{\alpha}_{3}$, from estimating equation 1 using alternative measures of culture. All coefficients are positive and statistically significant at the 5 percent level or lower, highlighting the relevance of gender social norms in the country of ancestry in explaining the gender smoking gap of second-generation immigrants in Spain.

According to estimates in column 1 , if a girl's parents, originally from a country with an "average" female-to-male smoking ratio, had instead come from a country with a female-to-male smoking ratio one standard deviation above the mean, the likelihood that she smokes in the host country would have increased by 4.6 percentage points relative to that of a male counterpart, an 84 percent increase relative to the observed gender smoking gap for immigrants of 5.5 percentage points (see Appendix Table A.2). Similarly, column 2 reveals that if a girl's parents, originally from a country with "average” GGI, had instead come 
from a country with a GGI one-standard deviation above the mean, her likelihood of smoking relative to a male counterpart would have been 3.9 percentage points higher, representing a 71 percent increase.

An alternative and complementary way to interpret these results follows. Let us take, for instance, the case of second-generation immigrant youths whose country of origin is Morocco, where the female-to-male smoking prevalence ratio and the GGI amount to 4.7 percent and 57.7 percent, respectively. Additionally, the smoking rate of girls from Moroccan ancestry in Spain is 1 percentage point lower than that of their male counterparts. If these youths' parents had come from the US instead, where the female to male smoking prevalence ratio and the GGI amount to 78.6 percent and 74.1 percent, respectively, our statistical model predicts that their gender smoking gap would be approximately 10.5 percentage points larger when considering either the female-to-male smoking prevalence ratio or the GGI as measures of culture. ${ }^{26}$ That is, the smoking gender gap among teenagers of Moroccan ancestry would raise from -1 to +9.5 percentage points if the female-to-male smoking ratio of Morocco took the US value instead or if Morocco’s GGI reached the US level.

\section{Institutional Channels from the Country of Ancestry Shaping Culture}

Because culture and institutions reinforce each other (Alesina and Giuliano, 2015), columns 3 to 7 in Table 3 explore which institutions in the country of ancestry shape the social norms regarding gender and smoking that end up being transferred to second-generation immigrants. In addition to assessing the sensitivity of our findings to alternative proxies of culture, this exercise enables us to identify which beliefs from the country of ancestry matter the most. Understanding the origin of the smoking gender gap will help design public health interventions that will be more efficient at preventing a potential epidemic of tobacco among women.

Columns 3 to 6 in Table 3 indicate that a one-standard deviation increase in the country-of-ancestry gender equality indices regarding women's

\footnotetext{
26 This is calculated as [Female to Male Smoking Ratio USA $_{\text {(0.786) - }}$ Female to Male Smoking Ratio Morocco $(0.047)=0.739] / 0.324 * \hat{\alpha}_{3}(0.046)=0.1049$ and $\left[G G I_{U S A}(0.741)-G G I_{\text {Morocco }}(0.577)=0.164\right] / 0.061 * \hat{\alpha}_{3}(0.039)=0.1048 . \quad$ Note that these calculations would not necessarily deliver so similar results in other cases.
} 
educational attainment, economic opportunities, or health and survival is associated with a 4.6, 3.6, or 3.3 percentage points increase in the smoking likelihood of girls relative to boys in the host country, the equivalent to an 83, 65, or 59 percent increase, respectively. These three effects are statistically significant at the 1 percent level. The effect of political empowerment is smaller (a 2.2 percentage points or 40 percent increase). Column 7 re-estimates the model but including the four different GGI components at the same time to explore which of these component is most relevant. In this specification, we observe that beliefs regarding women's educational attainment and health and survival are those that matter the most when explaining the gender differences in teenager smoking.

As Appendix Tables A.3 and A.4 show, our conclusions remain unchanged if we use a probit or a logit model instead of OLS and subsequently compute the average partial effects of the coefficients of interest.

For the sake of brevity, the paper will mostly present results using the GGI as a measure of gender equality. However, we have replicated the analysis below using alternative measures of culture, with similar results (shown in Appendix Table A.5).

\section{Other Determinants of Smoking and Omitted Variable Bias}

In this section we take a closer look at the relationship between gender social norms and the smoking gender gap by using a sequential approach that highlights how our coefficient of interests varies with the inclusion of additional covariates and sheds some light on the mechanisms through which the relationship between gender social norms and the gender smoking gap operates. In particular, we depart from a specification in which we only include a female indicator, year and province fixed effects, and then subsequently add several sets of covariates until we arrive to the baseline specification used in Table 3 . Finally, we add further covariates to our baseline specification to assess the relevance of various potential sources of omitted variable bias and how they may affect our conclusions.

Before presenting the results of these analyses, it is worth stressing that some of the additional characteristics that we will sequentially include (such as, for instance, parental education and work status as well as parental, siblings and 
peers' smoking) may well be affected by culture. Therefore, by including them, we are testing whether gender social norms transmitted from parents to children have a direct impact on the smoking gender gap beyond the indirect ways in which they could affect such gap through these variables. In other words, by including some of the controls we will introduce below we are limiting the avenues through which culture is allowed to operate and attempting to restrict them to those gender beliefs or preferences that parents transmit to their children. This is arguably a very demanding test of the relevance of culture. ${ }^{27}$ However, it is important to assess the sensitivity of our result to the inclusion of additional variables to the extent that they may capture underlying socioeconomic and behavioral differences across individuals rather than culture.

Column 1 in Table 4, in which we only control for the female indicator, and the year and province fixed effects, reveals that second-generation immigrant girls are, on average, 5.9 percentage points more likely to smoke than their male counterparts within province and year. Since the average smoking rate is 21.5 percent among second-generation boys, this implies that secondgeneration girls smoke, on average, 27.4 percent more than boys.

Column 2 adds to the specification in Column 1 the GGI and our main variable of interest, its interaction with the female dummy. According to this specification, beliefs regarding gender equality significantly affect the smoking decision of second-generation girls relative to their male counterparts. In particular, a one percentage-point increase in the standard deviation of the GGI in the country of ancestry is associated with a 3.6 percentage point increase in the likelihood that second-generation girls smoke relative to their male counterparts, which represents a 65 percent increase with respect to the raw smoking gender gap of 5.5 percentage points in our sample of second-generation immigrants. Interestingly, the country-of-ancestry GGI has no effect on the decision to smoke among second-generation boys.

\footnotetext{
${ }^{27}$ Note also that, as discussed in Section 2, by comparing outcomes across second-generation immigrants whose parents came to the host country from different countries of origin, the epidemiological approach is prone to underestimating the true effect of culture for two additional motives. First, cultural transmission is restricted to parents. Second, assimilation to the host country's culture is likely to weaken the impact of the country of ancestry's culture.
} 


\section{Culture versus Maternal Work Status}

Column 3 in Table 4 adds to the specification in Column 2 the age of the teenager at the time of the survey and its square, and his or her mother's and father's highest educational attainment as well as their labor force status. The reason for controlling for parental education and employment is that previous studies have documented a socioeconomic gradient in smoking (Gruber, 2001). We find that both being older and having a working mother increase the likelihood of smoking. In contrast, having a working father is associated with a lower likelihood of smoking. Nonetheless, adding these variables has little effect on our coefficient of interest, $\hat{\alpha}_{3}$. Indeed, the differential effect of the GGI on the likelihood that second-generation immigrant girls smoke relative to their male counterparts remains positive and statistically significant at the 1 percent level, and the size of the estimated coefficient has even slightly increased from 3.6 to 3.8 percentage points.

Because the socioeconomic gradient in smoking varies by country and gender (Cavelaars et al., 2000; Fukuda et al., 2005; Huisman, Kunst and Mackenback, 2005; and Laaksonen et al., 2003), Column 4, which corresponds with our benchmark specification presented in Table 3, interacts all the covariates added in Column 3 with the female indicator. Comparing Columns 3 and 4 in Table 4 reveals that none of these interacted variables are statistically significant, suggesting that youths' age and parental education and work status do not affect second-generation immigrant girls' and boys' smoking behavior differently. Only the country-of-ancestry gender equality measure has an effect on smoking that varies by gender and is statistically significantly different from zero.

\section{Other Sources of Omitted Variable Bias}

It may be that the results presented so far are capturing other factors (beyond gender social norms transmitted from parents to children) that affect the smoking gender gap.

For instance, it may be that our results are driven by how liquidity constrained teenage girls and boys are. If less liquidity constrained girls (relatively to boys), who may also happen to come from more gender-equal countries, smoke more relative to boys than more liquidity constrained girls 
(relatively to boys), who may happen to come from less gender-equal countries, failure to control for whether teenagers are cash constrained (and its interaction with the female dummy) may lead us to overestimate the link between gender equality and the smoking gender gap.

Similarly, if girls from less gender-equal countries perform academically worse (relative to their male counterparts) than girls from more gender-equal countries, ${ }^{28}$ leading to, say, higher grade retention rates for the former than the latter (relative to their male counterparts), failure to control for grade retention (and its interaction with the female indicator) may lead us to underestimate the effect of gender equality on the smoking gender gap, as evidence has shown that lower academic achievement is associated with higher smoking (US Department of Health and Human Services, 2010).

To address these two concerns, Column 5 in Table 4 presents a specification that controls for whether the adolescent works for pay or not, whether the adolescent has been retained a grade, and both of these variables interacted with the female indicator. While we find that both working and having been retained a grade have a positive and statistically significant effect on teenage smoking (regardless of gender), they have no gender differential effect. $^{29}$ Most importantly, adding these variables only reduces the size of our coefficient of interest, $\hat{\alpha}_{3}$, by 0.3 percentage points.

Parental smoking habits ${ }^{30}$ and family structure ${ }^{31}$ are other potentially relevant smoking determinants that, to the extent that they may be correlated with both the teenagers' gender and the degree of gender equality in their countries of ancestry, may affect our results. Column 6 in Table 4 addresses both concerns as it presents results from a specification that controls for whether both parents live in the household, and whether the mother or the father smokes and lives in the same household as the teenager. These three variables are also interacted with the female indicator to capture potentially differential effects by

\footnotetext{
${ }^{28}$ For instance, Nollenberger, Rodríguez-Planas, and Sevilla (2016) show that, the higher the degree of gender equality in the country of ancestry, the higher the performance of immigrant girls relative to boys in math.

${ }^{29}$ Note that the coefficients on the interactions are statistically insignificant and their magnitudes are close to zero.

${ }^{30}$ See for instance Loureiro, Sanz-de-Galdeano, and Vuri (2010) and the references therein.

31 There is evidence that youths from single-parent households are more likely to smoke than those from two-parent households (Du et al., 2015).
} 
gender. As expected, we find that living with both parents reduces the likelihood of smoking, and living with a smoking parent (either the mother or the father) increases the likelihood of smoking, but the effect of these variables does not significantly vary by gender. As $\hat{\alpha}_{3}=0.035$, a one standard-deviation increase in the country-of-ancestry GGI is associated with a relative increase in girls' likelihood to smoke relative to boys of 3.5 percentage points (or 64 percent of the 5.5 percentage point smoking gender gap observed in our sample of second-generation immigrants). Hence, the effect of culture on the smoking gender gap remains important, even after controlling for parental smoking habits and household composition.

Evidence has also shown the importance of peers in teenagers' smoking habits (Burt and Peterson, 1998). The specification shown in Column 7 controls for whether the individual has siblings who smoke in the household and whether the individual reports having seen students smoking in school within the past 30 days (and their interactions with the female indicator). Adding these controls increases $\hat{\alpha}_{3}$ to 0.036 , and it remains statistically significant at the 1 percent level. Our estimates suggest that having siblings who smoke in the household increases youth smoking, but has no gender differential effect. Similarly, seeing students smoke in school increases the odds of smoking, but has no gender differential effect on youth smoking.

Column 8 adds to the specification in column 7 an indicator variable that identifies teenagers who declare that "some, most, or all" of their friends smoke and its interaction with the GGI. Clearly this variable is endogenous and hence it is not surprising that, to the extent that culture affects peers' choices and is not only transmitted by parents but also by peers, it is picking up part of the effect of culture. Nonetheless, even in this specification, we find that $\hat{\alpha}_{3}$ is positive (at +0.025 , which represents a $45 \%$ of the smoking gender gap) and statistically significant at the 5 percent level.

As Appendix Table A.5 shows, our conclusions are basically unchanged if we use the female-to-male smoking ratio in the country of ancestry instead of GGI as our measure of gender equality. 


\section{Additional Robustness Checks}

This section discusses potential threats to our identification strategy and explores the robustness of our results to a battery of additional sensitivity checks, including alternative specifications and changes in sample criteria.

\section{Selective Migration and Geographic Clustering within the Host Country}

A common concern with the epidemiological approach is that second-generation immigrants may not be randomly selected. In our context, one may object from the outset and throughout that our teenagers' immigrant parents may not have the preferences/beliefs that are representative of the average in their country of origin. In this context, as other authors have previously remarked, ${ }^{32}$ an insignificant coefficient on the parental country of origin cultural proxy should not lead one to rule out the importance of culture. On the other hand, the interpretation of significant coefficients (as the ones we actually obtain) on the cultural proxies crucially depends on the issue being studied. However, we could not think of a plausible story such that selective migration would bias our results in favor of culture.

More specifically, in our case, if culture did not matter, our results being driven by selection would require the beliefs of parents from more/less gender equal countries to be systematically drawn from the opposite extremes of the countries' distributions of beliefs/preferences regarding female vs. male smoking. In particular, immigrant parents from more gender-equal countries would need to be disproportionally favorable (as compared to their nonimmigrant counterparts) towards women smoking (relative to men) and, in contrast, immigrant parents from less gender-equal countries would need to possess lower than average preferences towards female vs. male smoking habits. There is no reason to expect this to be the case.

Another potential concern with the epidemiological approach is that geographic sorting occurs within a given host country such that first-generation immigrants (that is, our teenagers' parents) self-select into certain areas. In our context, the concern would be that parents who care more about their daughters' success choose to move from countries of origin with low gender-equality

\footnotetext{
32 See for instance Fernández and Fogli (2009) and Fernández (2011).
} 
culture to regions in Spain with high-gender equality. Notice that this type of selection would bias our culture estimates downward (not upward), such that we would be underestimating the true effect of gender social norms on the smoking gender gap. At any rate, to address this concern, all of our regressions include province fixed effects, as indicated in equation (1). Hence, identification in our benchmark model (see Table 3) comes from comparing girls and boys from different ancestries who live in the same province, which is the smallest geographic area available in our dataset. Column 1 in Table 5 again reports results from our benchmark specification to facilitate further comparisons.

\section{Additional Controls and Alternative Specifications}

Column 2 in Table 5 presents findings from a specification that controls for the country-of-ancestry Gini index, which captures the extent to which the distribution of income among individuals within a country deviates from a perfectly equal distribution (with an index close to 1 being very unequal and an index close to 0 being very equal), and the interaction between the Gini index and the female indicator. We find no evidence that second-generation immigrants whose parents come from countries with greater inequality are more (or less) likely to smoke than those whose parents come from more equal countries (as the coefficient on the Gini index is close to zero and not statistically significant). Similarly, inequality in the country of ancestry has no effect on the youth smoking gender differential. Most importantly, controlling for country-of-origin Gini index and its interaction with gender equality has no effect on the coefficient $\hat{\alpha}_{3}$, which remains at +0.039 and statistically significant.

Alternatively, one may be concerned that our results may be picking up gender differential smoking patterns for second-generation immigrants whose parents come from countries of ancestry more similar to Spain. If that were the case, controlling for an indicator of whether the country of ancestry is a Spanishspeaking country and its interaction with the gender dummy would reduce the effect of the GGI on the smoking gender gap. In Column 3 in Table 5 we present a specification that controls for these two additional variables. Doing so has no effect on either the size or the significance of our coefficient of interest, $\hat{\alpha}_{3}$. 
Column 4 in Table 5 presents results from a more flexible specification in which each year fixed effect is interacted with the female indicator to allow the smoking gender gap to vary depending on the cohort being interviewed in each ESTUDES wave. Again, doing so has little effect on our coefficient of interest, $\hat{\alpha}_{3}$, which now amounts to 4 percentage points and remains statistically significant at the 1 percent level.

Column 5 in Table 5 shows that our estimates are robust to clustering the standard errors at the host-country province level, as opposed to using the country-of-ancestry fixed effects. Doing so reduces the significance of our coefficient of interest to the 5 percent level.

Another potential concern is that second-generation immigrants from different ancestries may face different economic and institutional environments within the host country that may in turn affect boys and girls differently. While it is the central government that regulates excise taxation, smoking restrictions and clean-air regulations in Spain, the regions (Comunidades Autónomas, CCAA hereafter) manage the delivery of health services. Hence, one may be worried that differential health services across CCAA that may affect gender differently are driving our results. To address this concern, column 6 in Table 5 adds to our baseline specification an interaction between the female indicator and CCAA fixed effects. Note that because we have province fixed effects in the specification, we cannot also have CCAA fixed effects. Column 7 in Table 5 presents the specification with both CCAA fixed effects and their interaction of the female indicator (now excluding provinces fixed effects). Results are similar in both specifications. While our coefficient of interest, $\hat{\alpha}_{3}$, becomes smaller (it is now +0.025 ), it remains positive and statistically significant at the 5 percent level, indicating that gender social norms continue to explain a relevant share (45 percent) of the smoking gender gap even after controlling for potential gender differences in the delivery of health services at the CCAA level.

Column 8 in Table 5 presents a specification in which the GGI is replaced with country-of-ancestry fixed effects. ${ }^{33}$ This specification is more

\footnotetext{
${ }^{33}$ The important advantages of using quantitative variables as proxies for culture, as we do in the rest of the paper, are that they allow one to be explicit as to why culture may matter and they facilitate thinking about potentially omitted variables.
} 
flexible as it does not require the relationship between culture and smoking to be linear in our cultural proxy. Moreover, the country-of-ancestry fixed effects accounts for the cultural features captured by the GGI and for any other cultural factors not related to gender equality that may affect boys' and girls' smoking in the same way. Doing so has very little effect on our coefficient of interest: $\hat{\alpha}_{3}$ is now 0.036 and remains statistically significant at the 1 percent level.

\section{Changes in Sample Criteria}

Table 6 shows that our results are not driven by specific groups of secondgeneration immigrants and/or certain countries of ancestry having disproportionally large numbers of observations. Column 1 presents our baseline estimation to facilitate comparisons, while Columns 2 to 4 present the results obtained when dropping the three countries of ancestry (one at a time) with the largest number of immigrants currently in the country, that is, Morocco, Ecuador and Romania (Rodríguez-Planas and Vegas, 2014). Additionally, Columns 2, 5, 6 and 7 present the results obtained when dropping the four countries of ancestry (one at a time) with the largest number of secondgeneration immigrants in our sample, that is: Morocco, France, Germany and Venezuela. Doing so has little effect on our main result. Only in the case of Moroccans, the largest group of second-generation immigrants by far, do we lose some precision as the effect of the GGI on the smoking gender gap is only statistically significant at the 10 percent level.

\section{Heterogeneity}

In this section we explore whether the transmission of cultural beliefs on the role of women in society varies across different types of second-generation immigrants by estimating our baseline specification for different subgroups. The first two columns of Table 7 present the coefficient of interest estimated for a particular subgroup of second-generation immigrants, while column 3 displays the p-value obtained when testing against the null hypothesis of equality of coefficients across subgroups.

Panels A and B of Table 7 explore whether the impact of culture on the smoking gender gap differs by maternal educational attainment and work status, respectively. Column 1 in Panel A shows that culture matters in determining the 
smoking gender gap of second-generation immigrants whose mother did not reach high-school, suggesting that maternal (lack of) human capital mediates in the transmission of beliefs. In contrast, the effect of culture on the smoking gender gap is two thirds smaller in size and not statistically significant for second-generation immigrants whose mother has at least some secondary education (see column 2 in Panel A). Column 3 shows that this differential impact of culture is statistically significant at the 5 percent level.

Panel B shows that there is no differential effect of culture on the smoking gender gap depending on whether mothers work or not. Indeed, we find that the effect of culture on the smoking gender gap is +0.036 and +0.037 for either group. Both coefficients are statistically significant at the 1 percent level. Similarly, Panel C of Table 7 shows that family structure (living in oneor two-parent household) does not seem to mediate in the transmission of beliefs. The effect of culture on the smoking gender gap is +0.038 and +0.039 and statistically significant at the $1 \%$ and $10 \%$ level for single- and two-parent households, respectively.

Moving now to panel D in Table 7, we observe that the coefficient of interest is twice as large (and statistically significantly so at the 10.7 percent level) when cohabiting siblings smoke than when they do not. Because siblings' smoking habits and those of the teenager are likely to be jointly determined, caution is needed when interpreting these findings. Nonetheless, it is important to note that even for those teenagers whose siblings do not smoke, gender social norms affect the smoking gender gap as the coefficient of interest is +0.035 and statistically significant at the 5 percent level for this subgroup.

Panels E explores whether the effect of culture varies when "all, most or some" friends smoke versus "few or no" friends smoke. ${ }^{34}$ To the extent that individuals choose their friends, some caution is (again) needed when interpreting these results. Panel E shows that the transmission of beliefs is three times larger (and statistically significantly so at the 5 percent level) for those whose friends also smoke. Again we find that even among those adolescents with few or no friends who smoke, second-generation immigrant girls whose

\footnotetext{
${ }^{34}$ Similar findings are obtained when comparing teens for whom all or most friends smoke versus few or no friends smoke.
} 
country of ancestry is more gender equal are more likely to smoke (relative to boys) than those girls from less gender-equal countries of ancestry. The effect is +0.013 (statistically significant at the 5 percent level). Panels D and E suggest that, while siblings and peers' smoking behavior reinforces the transmission of beliefs, gender social norms continue to affect the gender smoking gap even when they do not smoke.

Finally, Panel F explores whether culture has a differential effect on the smoking gender gap depending on the concentration level of immigrants from the same country of origin in the province. We calculate the proportion of immigrants in each province from the same country of origin by dividing the number of immigrants from a particular country of birth in province $k$ by the population (including natives and immigrants) in that particular province. ${ }^{35}$ Even though the effect of culture on the smoking gender gap is twice as large for teenagers living in a province with a concentration of immigrants from the same ethnicity below the median ethnic concentration in the province, we cannot reject the null hypothesis that the effect of culture is the same for teenagers living in relatively high- and low-ethnic concentration provinces Most importantly, the impact of culture on the smoking gender gap is relevant for those living in both high- and low-ethnic concentration provinces, with the effects being statistically significant at the 1 percent level in both cases. ${ }^{36}$

\section{Gender Social Norms and Other Risky Outcomes}

In this section we explore the effect of country-of-ancestry gender social norms on other risky behaviors, namely the decision to drink alcohol, get drunk, binge drink (defined as drinking more than 5 drinks within two hours), smoke marijuana (during the past 30 days), get into a fight, and being arrested (during the past year).

The legal drinking age in Spain was increased by two years from 16 to 18 years in 2003. Nonetheless, drinking has always been part of the Spanish culture. Traditionally, youth began drinking in the presence of adult family

\footnotetext{
${ }^{35}$ Immigrant and native populations at the province level and by country of origin are obtained from the 2001 Census.

${ }^{36}$ This finding contrasts with those of Fernández and Fogli (2009) and Luttmer and Singhal (2011), who find a stronger impact of culture for immigrants who have a greater tendency to cluster with their ethnic community.
} 
members. However, with the arrival of the democracy in1977, drinking among peers and outside the household became much more common (Heath, 1995), and alcohol consumption currently begins at an early age in Spain, around 13-14 years old (Ministerio de Sanidad, 2013).

In our sample of second-generation immigrants, 53, 23 and 30 percent of youths report having consumed alcohol, got drunk and binge drunk within the past 30 days, respectively. While there are no gender differences in the probability of consuming alcohol or getting drunk of second-generation immigrants, teenage boys in our sample are, on average, significantly more likely to have binge drunk (32 versus 28 percent) and smoked marijuana in the past 30 days (17 versus 14 percent) as well as more likely to have been involved in a fight (28 versus 14 percent) and have been arrested (11 versus 5 percent) within the past year than their female counterparts.

Moving now to Table 8 , columns 1 to 3 indicate that a one standard deviation increase in the country-of-ancestry GGI is associated with a 4.8, 3.5 and 1.9 percentage points higher probability of consuming alcohol, getting drunk and binge drinking for teenage girls relative to boys, representing a 9, 15, and 6.3 percent increase with respect to the average prevalence of these behaviors, respectively. While there is no gender gap in our raw data for the probability of consuming alcohol and getting drunk, boys are more prone to binge drinking than girls by 3.58 percentage points. Hence, our estimate for binge drinking (Column 3 in Table 8) accounts for 53 percent of the gender gap in binge drinking. The first two effects are statistically significant at the 1 percent level, while the third one is only significant at the 10 percent level.

Along the same lines, Columns 4 and 5 in Table 8 reveal that descending from a country of ancestry with a GGI one-standard deviation above the mean is associated with a 2.2 and 3.1 percentage points higher probability of smoking marijuana and being involved in a fight for girls relative to boys, representing a 14 and 15 percent increase with respect to the mean prevalence of these behaviors, respectively. If instead we compare our estimated effects with the corresponding mean gender gaps in our sample (which amount to 3.4 and 14 percentage points for the probability of smoking marijuana and being involved in a fight, respectively), they account for 29 percent and 22 percent of such gaps. Both estimates are statistically significant at the 5 percent level. While we find 
no significant effect of culture on the likelihood of being arrested (see Column 6 of Table 8), estimates in Table 8 are mostly consistent with those obtained for smoking.

Overall, Table 8 strongly suggests that descending from more genderequal countries makes female teenagers relatively more likely than male teenagers to engage in risky behaviors that go beyond smoking.

\section{Investigating Potential Mechanisms: Perceived Risks of Smoking, Information Patterns, Parental Discipline and Access to Tobacco}

This section further explores potential mechanisms behind our results. To do so, we now change the dependent variable and replace it with different measures of: teenagers' beliefs about the health effects of smoking; perceptions regarding drug-related information; main sources of information on drugs; parental rules regarding their teenagers' behavior inside and outside the home, as well as their smoking habits; and teenagers' access to tobacco.

We carry out this investigation in two steps. First, in Table 9, we explore whether there are significant gender differences in the aforementioned outcome variables by estimating regressions that include a female indicator as well as all the individual controls in our baseline specification (not interacted with gender), province and year fixed effects. This specification clusters the standard errors at the province level. Second, Table 10 re-estimates our baseline specification with the alternative outcome variables in order to identify whether gender social norms affect differentially these various outcomes for girls and boys.

We observe that second-generation immigrant girls perceive higher risks of heavy smoking but somewhat lower risks of occasional smoking than their male counterparts (Panel A, Table 9). Indeed, second-generation immigrant girls are more likely than their male counterparts to think that smoking one pack of cigarettes a day is harmful for one's health (Columns 2 and 4, Panel A, Table 9). Both coefficients are statistically significant at the 1 percent level. In contrast, column 3 shows that second-generation immigrant girls are less likely than their male counterparts to think that smoking sometimes is harmful (albeit this coefficient is only statistically significant at the 10 percent level). Despite 
these gender differences in risk perception, there is no evidence of any gender differential effect of culture on the perceived risks of smoking (Panel A, Table $10)$.

In Panel B of Tables 9 and 10 we turn to the role played by the perceived amount of information about drugs received by teenagers, as well as the sources of this information. Interestingly, second-generation immigrant girls are less likely than their male counterparts to perceive that they are fully informed about drugs (Column 1, panel B, Table 9). However, there is no evidence that such perception significantly differs among girls and boys depending on whether their parents come from more (or less) gender equal countries (Column 1, Panel B, Table 10). ${ }^{37}$

Panel B in Table 9 also shows that second-generation immigrant girls and boys sometimes also differ when it comes to their main sources of information on drugs. While girls are significantly less likely than boys to cite their fathers as one of their main sources of information on drugs (Column 3), they are more likely than boys to refer to their teachers or health professionals (Columns 6 and 7, respectively) as relevant sources of information on drugs. Similarly, girls are also more likely than boys to have been asked about tobacco consumption by a doctor (Column 9). In sum, it appears that girls are more likely than boys to rely on doctors, teachers and health professionals to gather information on drugs, while boys are more likely to rely on their fathers.

Interestingly, Panel $\mathrm{B}$ in Table 10 shows that second-generation immigrant girls from more gender-equal countries are more likely, relative to boys, to receive information regarding drugs from their fathers (Column 3) or their friends (Column 5), but less likely to obtain it from the internet (Column 9). Hence, in this case, there is suggestive evidence that gender social norms affect boys and girls differently in terms of how they gather information on drugs. This result should be interpreted with caution because, to the extent that second-generation immigrant girls from more gender-equal countries are more

\footnotetext{
${ }^{37}$ We obtain similar results if instead of analyzing teenagers' propensity to consider themselves fully informed about drugs we analyze the probability that they perceive themselves as fully or sufficiently informed about drugs.
} 
likely to smoke (relative to boys) than those from less gender-equal countries, the fact that worried fathers and friends are more likely to talk about drug use with them may be a consequence (not necessarily a cause) of their higher propensity to smoke.

It is also worthwhile to highlight that second-generation immigrant girls whose parents come from more gender-equal countries do not receive more (or less) information about drugs from health professionals or teachers (relative to boys) than those whose parents come from less gender-equal countries (Columns 6 and 7, Panel B, Table 10), suggesting that there is no discrimination against or targeting towards a particular group of second-generation immigrant girls from more (or less) gender-equal ancestries.

Next, we explore how strict parents are inside and outside the home (Panel C of Tables 9 and 10), how tolerant they are towards their teenagers' smoking behavior and how easy it is for teenagers to obtain cigarettes (Panel D of Tables 9 and 10). We find that second-generation teenage girls are more likely to be closely monitored by their parents when they go out at night than their male counterparts (Columns 3 and 4, Panel C, Table 9). Moreover, girls' parents are also more likely than boys' parents to establish a clear set of rules regarding what their teenagers can do outside the household (Column 2, Panel C, Panel 9), although this gender gap is only statistically significant at the $10 \%$ level. Interestingly, the opposite appears to happen inside the household, where teenage girls are less likely to face a clear set of rules than teenage boys (Column 1, Panel C, Table 9). Additionally, there is no evidence of a statistically significant gender gap as far as parental leniency towards smoking is concerned (Columns 1-4, Panel D, Table 9), while girls are significantly more likely than boys to declare that cigarettes are very easy to get (Column 5, Panel D, Table 9).

Panel C of Table 10, in turn, suggests that at least some aspects related to parental discipline and monitoring may play a role in explaining the association between gender social norms and the gender smoking gap that we have uncovered in previous sections. In particular, gender equality in the country of ancestry reduces the likelihood that parents monitor girls more closely than boys 
when they go out at night (Columns 3 and 4, Panel C, Table 10). Along these lines, although we found no gender gap in parental leniency towards smoking (Columns 1 and 2, Panel D, Table 9), Panel D in Table 10 (Column 2) indicates that second-generation immigrant girls from more gender-equal countries are more likely to have a mother who allows them to smoke outside of the family household-albeit this effect is only statistically significant at the 10 percent level. Finally, while we know that second-generation immigrant girls are more likely than boys to have very easy access to cigarettes (Column 5, Panel D, Table 9), we also observe that this gender gap is larger among teenagers whose parents come from more gender-equal countries than among those whose parents come from less gender-equal countries (Column 5, Panel D, Table 10).

Overall, the evidence presented in this section is suggestive that genderrelated beliefs are being transmitted at least in the following two ways: parental monitoring and easy access to cigarettes.

\section{Conclusion}

This paper identifies the relevance of gender social norms in explaining youths' gender differences in smoking, contributing to an emerging literature on how beliefs affect behavioral outcomes. Crucially, this paper is the first to provide evidence that cultural attitudes towards gender equality affect behaviors with potentially devastating health consequences, and that they do so differently for male and female teenagers. In particular, we show that descending from more gender-equal societies makes girls relatively more prone than boys to smoke. Moreover, the evidence indicates that the size of the effect of gender social norms on the smoking gender gap is large: if a girl's parents, originally from a country with "average” GGI, had instead come from a country with a GGI onestandard deviation above the mean, her likelihood of smoking relative to a male counterpart would have been between 2.5 and 3.9 percentage points higher, representing a 44 to 71 percent increase, depending on the specification. Our results are remarkably robust to a wide battery of sensitivity checks and to the use of alternative cultural proxies such as the female-to-male smoking ratio in the country of ancestry. Our findings suggest that gender-tailored smoking 
reduction and cessation interventions need to account for differences in gender social norms, and possibly consider modifying them directly.

We also identify which mechanisms mediate the transmission of beliefs, and find that while mothers' lack of human capital is an important channel, family structure or maternal employment are not. We also provide evidence that parental monitoring and easy access to cigarettes facilitate the transmission of gender social norms. Despite there being gender differences in terms of teenagers' perceived risks of smoking and in their patterns of acquisition of drug-related information, we do not find an association between these gender differences among second-generation immigrants and the gender social norms of their countries of ancestry. Altogether the evidence seems to point that girls' differential smoking is the result of having internalized certain beliefs on the stage of the diffusion of innovation or the epidemic they are in - which is not the actual stage in the host country, but that of their parents' country of origin.

Last but not least, our findings highlight that girls whose parents come from more gender-equal societies are also relatively more likely to engage in risky behaviors than their male counterparts. As these risky behaviors are traditionally male risky behaviors, our study suggests that gender equality moves females' behaviors closer to those of males. While others have shown that more gender-equal societies are beneficial to girls' math test scores relative to those of boys (Nollenberger, Rodríguez-Planas, and Sevilla, 2016; Guiso, Monte, Sapienza, and Zingales, 2008; and Fryer and Levitt, 2010), this paper brings to light the detrimental effects of gender equality on unhealthy behavioral outcomes.

\section{References}

Adda, J. and F. Cornaglia. 2006. "Taxes, Cigarette Consumption and Smoking Intensity.”, American Economic Review, 96(4): 1013-1028.

Adda, J. and F. Cornaglia. 2010. "The Effect of Taxes and Bans on Passive Smoking.”, American Economic Journal: Applied Economics, 2(1), 1-32.

Alesina, Alberto and Paola Giuliano. 2015. "Culture and Institutions.” Journal of Economic Literature 53(4): 898-944.

Almond, Douglas, Lena Edlund, and Kevin Milligan. 2013. "Son Preference and the Persistence of Culture: Evidence from South and East Asian Immigrants to Canada.” Population and Development Review 39(1): 75-95. 
Antecol, H. 2000. "An Examination of Cross-Country Differences in the Gender Gap in Labor Force Participation Rates.” Labour Economics 7(4): 409-26.

Baska T., C. Warren, M. Baskova, and N. Jones. 2009. "Prevalence of Youth Cigarette Smoking and Selected Social Factors in 25 European Countries: Fndings from the Global Youth Tobacco Survey." Int J Public Health 54:439-445

Bauer T, Göhlmann S, Sinning M. 2007. "Gender differences in smoking behavior.” Health Economics 16 (9): 895-909.

Bethel, J, and M. Schenker. 2005. "Acculturation and Smoking Patterns among Hispanics: a Review.” American Journal of Preventive Medicine 29, 143148.

Blau, Francine D., Lawrence M. Kahn, AlbertYung-Hsu Liu, and Kerry L. Papps. 2013. “The Transmission of Women's Fertility, Human Capital, and Work Orientation across Immigrant Generations.” Journal of Population Economics 26(2): 405-35. http://dx.doi.org/10.1007/s00148-012-0424-x.

Cavelaars, A. E., Kunst, A. E., Geurts, J. J., Crialesi, R., Grotvedt, L. Helmer, U., et al. 2000. "Educational Differences in Smoking: International Comparison.” British Medical Journal, 320 (7242), 1102-1107.

Burt, R. and A. Peterson, Jr. 1998. "Smoking Cessation among High School Seniors.” Preventive Medicine, 27(4), 319-327.

Carroll, Christopher D., Byung-Kun Rhee, and Changyong Rhee. 1994. "Are There Cultural Effects on Saving? Some Cross-Sectional Evidence.” The Quarterly Journal of Economics 109(3): 685-99.

Chaloupka, F.J. and Wechsler, H. 1997. "Price, Tobacco Control Policies and Smoking Among Young Adults.” Journal of Health Economics 16: 359373.

Chaloupka, F.J., Pacula, R.L. 1999. "Sex and Race, Differences in Young People's Responsiveness to Price and Tobacco Control Policies.” Tobacco Control, 8:373-377.

Choudhury S. M. Kengganpanich, S. Benjakul, et al. 2010. “Differences by Sex in Tobacco Use and Awareness of Tobacco Marketing-Bangladesh, Thailand, and Uruguay, 209.” M M W R Morb Mortal Wkly Rep, 59:61319.

Chung, W., S. Lim, and S. Lee. 2010. "Factors Influencing Gender Differences in Smoking and their Separate Contributions: Evidence from South Korea." Social Science \& Medicine, 70: 1966-1973.

Christelis, D. and Sanz-de-Galdeano, A. 2011. "Smoking Persistence Across Countries: A Panel Data Analysis.” Journal of Health Economics 30: 10771093. 
Christopoulou, Rebekka, and Dean R. Lillard. 2015. "Is smoking behavior culturally determined? Evidence from British immigrants." Journal of economic behavior \& organization 110: 78-90.

Colman, G., M. Grossman and T. Joyce. 2003. "The Effect of Cigarette Excise Taxes on Smoking Before, During and After Pregnancy.” Journal of Health Economics 22(6): 1053-1072

Cummings K., C. Morley, J. Horan, C. Steger, N-R. Leavell. 2002. "Marketing to America's Youth: Evidence from Corporate Documents.” Tob Control, 11 (suppl 1):15-17.

Du Y., P. Palmer, K. Sakuma, J. Blaike, and A. Johnson. 2015. "The Association Between Family Structure and Adolescent Smoking Among Multicultural, Students in Hawaii.” Preventive Medicine Reports 2, 206212.

Eugster, Beatrix, Rafael Lalive, Andreas Steinhauer, and Josef Zweimüller. 2011. “The Demand for Social Insurance: Does Culture Matter?” The Economic Journal 121: 413-48.

Ezzati M, Lopez AD. 2003. “Estimates of Global Mortality Attributable to Smoking in 2000. Lancet; 362:847-52.

Fernández, Raquel. 2007. "Women, Work and Culture." Journal of the European Economic Association 24(4): 329-30.

Fernández, Raquel, and Alessandra Fogli. 2006. "Fertility: The Role of Culture and Family Experience." Journal of the European Economic Association 4(2-3): 552-61.

Fernández, Raquel. 2008. “Culture and Economics.” New Palgrave Dictionary of Economics, 2nd edition.

Fernández, Raquel, and Alessandra Fogli. 2009. "Culture: An Empirical Investigation of Beliefs, Work, and Fertility.” American Economic Journal: Macroeconomics 1(1): 146-77.

Fernández, Raquel. 2011. “Does Culture Matter?” Published in, J. Benhabib, M. O. Jackson and A. Bisin, editors, Handbook of Social Economics, Vol. 1A, North-Holland.

Ferrence R.G. 1989. "Deadly Fashion: The Rise and Fall of Cigarettes in North America.” New York: Garland.

French Davina J., Soong-Nang Jang, Robert J. Tait, Kaarin J. Anstey. 2013. "Cross-national gender differences in the socioeconomic factors associated with smoking in Australia, the United States of America and South Korea." International Journal of Public Health, Volume 58, Issue 3, pp 345-353.

Fryer, Ronald, and Steven Levitt. 2010. “An Empirical Analysis of the Gender Gap in Mathematics.” American Economic Journal: Applied Economics 
2(2): 210-40.

Furtado, Delia, Miriam Marcén, and Almudena Sevilla. 2013. "Does Culture Affect Divorce? Evidence from European Immigrants in the United States." Demography 50(3): 1013-38.

Fukuda, Y., K. Nakamura, K., and T. Takano. 2005. "Socioeconomic Pattern of Smoking in Japan: Income Inequality and gender and age differences.” Annals of Epidemiology, 15 (5): 365-372.

Gilleskie, D. and K.S. Strumpf. 2005. "The Behavioral Dynamics of Youth Smoking.” The Journal of Human Resources 40(4): 822-866.

Giuliano, Paola. 2007. "Living Arrangements in Western Europe: Does Cultural Origin Matter?” Journal of the European Economic Association 5(September): 927-52.

Gorman B. J. Lariscy, and C. Kaushik. 2014. "Gender, Acculturation, and Smoking Behavior among U.S. Asian and Latino Immigrants.” Social Science \& Medicine, 106: 110-118.

Gruber, J. 2001a. "Youth Smoking in the 1990s: Why Did it Rise and What are the Long-Run Implications?” American Economic Review. May, 91:2, 8590 .

Gruber, J. 2001b. “Tobacco at the Crossroads: The Past and Future of Smoking Regulation in the United States.” The Journal of Economic Perspectives, Vol 15, no. 2: 193-212.

Gruber, J. and J. Zinman. 2000. "Youth Smoking in the U.S.: Evidence and Implications.” Risky Behaviors among Youth: An Economic Analysis. Chicago: University of Chicago Press.

Guindon GE, Boisclair D. 2003. "Past, Current and Future Trends in Tobacco Use.” HNP discussion paper. Washington: The World Bank.

Guiso, Luigi, Paola Sapienza and Luigi Zingales. 2006. "Does Culture Affect Economic Outcomes?." Journal of Economic Perspectives, 20(2): 23-48.

Guiso, Luigi, Ferdinando Monte, Paola Sapienza, and Luigi Zingales. 2008. “Culture, Gender, and Math.” Science (New York, N.Y.) 320: 1164-65.

Haglund Margareth. 2010. "Women and Tobacco: A Fatal Attraction.” Bulletin of the World Health Organization; 88:563-563.

Heath D. 1995. International Handbook on Alcohol and Culture. Greenwood Publishing Group, ISBN: 0313252343, 9780313252341, 391 pages.

Hersch, J. 2000. "Gender, Income Levels, and the Demand for Cigarettes.” Journal of Risk and Uncertainty. 21:264-282. 
Hitchman SC, Fong GT. 2011. "Gender Empowerment and Female-to-Male Smoking Prevalence Ratios”. Bull World Health Organ; 89:195-202.

Huisman, M., A.E. Kunst, and J.P. Mackenbach. 2005. "Inequalities in the Prevalence of Smoking in the European Union: Comparing Education and Income.” Preventive Medicine, 40 (6), 756-764.

Kaplan M, Carriker L, Waldron I. 1990. "Gender Differences in Tobacco Use in Kenya.” Social Science \& Medicine. 30:305-10.

Laaksonen, M., R. Prattala, V. Helasoja, A. Uutela, and E. Lahelma. 2003. "Income and Health Behaviours. Evidence from Monitoring Surveys among Finnish Adults.” Journal of Epidemiology and Community Health, 57(9), 711-717.

Leigh and Leung. 2014. "Healthy and Unhealthy Assimilation: Country of Origin and Smoking Behavior among Immigrants.” Health Economics 23: 1411-1429.

Loureiro M., A. Sanz-de-Galdeano, and D. Vuri, 2010. "Smoking Habits: Like Father, Like Son, Like Mother, Like Daughter.” Oxford Bullletin of Economcis and Statistics, 72 (6), 717-743.

Luttmer, Erzo F. P, and Monica Singhal. 2011. "Culture, Context, and the Taste for Redistribution.” American Economic Journal: Economic Policy 3(1): 157-79.

Mackay, J. and Amanda Amos. 2003. “Women and Tobacco” Respirology. 8:123-130.

Mackay, J., Eriksen, M. P., Shafey, O., \& American Cancer Society. 2006. The tobacco atlas (2nd ed.). Atlanta, Ga.: American Cancer Society.

Ministerio de Sanidad. 2013. "Informe sobre la Encuesta sobre el Uso de Drogas en Enseñanzas Secundarias en España (ESTUDES), 1999-2012.” Gobierno de España.

Müller, F., F. and L. Wehbe 2008. "Smoking and smoking cessation in Latin America: a review of the current situation and available treatments." Int $J$ Chron Obstruct Pulmon Dis. Jun; 3(2): 285-293.

Nathanson C. 1995. "Mortality and the Position of Women in Developed Countries”. In: Lopez AD, Caselli G, Valkonen T, editors. Adult Mortality in Developed Countries: From Description to Explanation. Oxford: Clarendon; pp. 135-57.

National Cancer Institute. 2008. "The Role of the Media in Promoting and Reducing Tobacco Use.” Tobacco Control Monograph 19. Bethesda, MD, USA: US Department of Health and Huma Services. National Institute of Health, National Cancer institute, 2008. 
Nollenberger, N., N. Rodríguez-Planas, and A. Sevilla. 2016. "The Math Gender Gap: The Role of Culture." American Economic Review, vol. 106, no. 5, pp. 257-61.

North, D. 1990. Institutions, Institutional Change, and Economic Performance. New York: Cambridge University Press.

Osili U., and A Paulson, 2008. "Institutions and Financial Development: Evidence from International Migrants in the United States," Review of Economics and Statistics. 90(3): 498-512.

Pampel FC. 2001. "Cigarette Diffusion and Sex Differences in Smoking." Journal of Health and Social Behavior; 42:388-404.

Pampel FC. 2003. "Declining Sex Differences in Mortality from Lung Cancer in High-Income Nations.” Demography; 40:45-65.

Pampel, F. C. 2006. "Global Patterns and Determinants of Sex Differences in Smoking.” Int J Comp Sociol.; 47(6): 466-487.

Payne, S. 2005. “Gender in Lung Cancer and Smoking Research.” Geneva: World Health Organization.

Polavieja, J. 2015. “Capturing Culture: A New Method to Estimate Exogenous Cultural Effects Using Migrant Populations.” American Sociological Review, vol. 80 (1), pages 166-191.

Rodriguez-Planas N. and R. Vegas. 2014. "Do Moroccans Fare Better or Worse than other Migrants in Spain?” Middle East Development Journal, vol. 3(02), pages 119-139.

Rogers E.M. 1995. Diffusion of Innovations. $4^{\text {th }}$ Edition, New York: Free Press.

Shaap M. M., A. E. Kunst, M. Leinsalu, E. Regidor, A. Espelt, O. Ekholm, et al., 2009. "Female Ever-Smoking, Education, Emancipation and Economic Development in 19 European Countries.” Soc Sci Med, 68: 1271-8.

Strang D. and S.A. Soule. 1998. "Diffusion and Innovation in Social Movements: From Hybrid Corn to Poison Pills.” Annual Review of Sociology, 24:265-90.

Townsend J., P. Roderick, and J. Cooper. 1994. "Cigarette Smoking by Socioeconomic Group, Sex, and Age: Effects of Price, Income, and Health Publicity.” British Medical Journal. 309: 923-927.

US Department of Health and Human Services. 2010. "Tobacco Use and Academic Achievement”. Center for Disease Control and Prevention. 
Waldron I. 1991. "Patterns and Causes of Gender Differences in Smoking." Soc Sci Med; 32: 989-1005.

Waldron I, Bratelli G, Carriker L, Suno W, Vogeli C, Waldman E. Gender Differences in Tobacco Use in Africa, Asia, the Pacific, and Latin America. Social Science \& Medicine. 1988; 27:1269-75.

Warren CW, Jones NR, Eriksen MP, Asma S. Global Tobacco Surveillance System (GTSS) collaborative group. 2006. "Patterns of global tobacco use in young people and implications for future chronic disease burden in adults.” Lancet; 367: 749-53.

WHO. 1992. World Health Organization (WHO) Women and Tobacco. Geneva: World Health Organization; 1992.

WHO 2008. WHO report on the global tobacco epidemic, 2008: the MPOWER package. Geneva: World Health Organization; 2008.

WHO 2009. Women and health: today's evidence, tomorrow's agenda. Geneva: World Health Organization.

WHO 2010. 10 Facts on Gender and Tobacco. Geneva: World Health Organization.

WHO 2011. WHO Report on the Global Tobacco Epidemic. Geneva: World Health Organization.

Yen, S.T. 2005. "Zero Observations and Gender Differences in Cigarette Consumption.” , 37:1839-1849.

Zhang, J., and Z. Wang. 2008. "Factors Associated with Smoking in Asian American Adults: A Systematic Review.” Nicotine \& Tobacco Researh 10, 791-801. 

by Country of Ancestry

\begin{tabular}{|c|c|c|c|c|c|c|c|c|c|c|c|}
\hline & & & In Spain & & & In C & ountry & Ancest & & & \\
\hline & & (1) & (2) & (3) & (4) & $(5)$ & $(6)$ & (7) & (8) & (9) & (10) \\
\hline & Country of & Smoking & Female & Male & $\mathrm{F} / \mathrm{M}$ & GGI & GGI & GGI & GGI & GGI & $N$ \\
\hline & ancestry & & smoking & smoking & smoking & & Ec. & Educ. & Pol. & $\mathrm{H} \& \mathrm{~S}$ & \\
\hline & & & & likelihood & & & & & & & \\
\hline 1 & Austria & -0.554 & 0.071 & 0.625 & 0.946 & 0.709 & 0.595 & 0.989 & 0.274 & 0.979 & 22 \\
\hline 2 & Bolivia & -0.333 & 0.167 & 0.500 & 0.550 & 0.675 & 0.596 & 0.959 & 0.174 & 0.972 & 10 \\
\hline 3 & Australia & -0.286 & 0.214 & 0.500 & 0.806 & 0.727 & 0.743 & 1.000 & 0.192 & 0.974 & 28 \\
\hline 4 & India & -0.197 & 0.053 & 0.250 & 0.119 & 0.615 & 0.403 & 0.837 & 0.291 & 0.931 & 31 \\
\hline 5 & Senegal & -0.197 & 0.167 & 0.364 & 0.042 & 0.641 & 0.644 & 0.821 & 0.127 & 0.973 & 17 \\
\hline 6 & Gambia & -0.167 & 0.000 & 0.167 & 0.114 & 0.676 & 0.759 & 0.829 & 0.138 & 0.980 & 15 \\
\hline 7 & Norway & -0.143 & 0.000 & 0.143 & 0.968 & 0.840 & 0.831 & 1.000 & 0.561 & 0.970 & 11 \\
\hline 8 & Russia & -0.139 & 0.417 & 0.556 & 0.366 & 0.704 & 0.736 & 0.999 & 0.100 & 0.979 & 21 \\
\hline 9 & El Salvador & -0.133 & 0.200 & 0.333 & 0.352 & 0.660 & 0.553 & 0.988 & 0.118 & 0.980 & 11 \\
\hline 10 & Syria & -0.119 & 0.214 & 0.333 & 0.196 & 0.593 & 0.398 & 0.936 & 0.060 & 0.976 & 26 \\
\hline 11 & China & -0.106 & 0.065 & 0.171 & 0.044 & 0.688 & 0.693 & 0.981 & 0.149 & 0.929 & 81 \\
\hline 12 & Mexico & -0.028 & 0.255 & 0.283 & 0.335 & 0.658 & 0.521 & 0.991 & 0.139 & 0.980 & 101 \\
\hline 13 & Ecuador & -0.017 & 0.250 & 0.267 & 0.239 & 0.707 & 0.599 & 0.988 & 0.266 & 0.976 & 35 \\
\hline 14 & Philippines & -0.014 & 0.231 & 0.245 & 0.204 & 0.765 & 0.761 & 1.000 & 0.321 & 0.980 & 88 \\
\hline 15 & Morocco & -0.010 & 0.116 & 0.126 & 0.047 & 0.577 & 0.408 & 0.861 & 0.067 & 0.971 & 1,108 \\
\hline 16 & Switzerland & 0.008 & 0.287 & 0.279 & 0.743 & 0.756 & 0.727 & 0.989 & 0.335 & 0.974 & 169 \\
\hline 17 & Poland & 0.014 & 0.214 & 0.200 & 0.759 & 0.704 & 0.653 & 0.999 & 0.184 & 0.979 & 29 \\
\hline 18 & Algeria & 0.015 & 0.375 & 0.360 & 0.012 & 0.605 & 0.467 & 0.953 & 0.035 & 0.966 & 41 \\
\hline 19 & Uruguay & 0.023 & 0.203 & 0.180 & 0.743 & 0.690 & 0.657 & 1.000 & 0.123 & 0.980 & 119 \\
\hline 20 & Portugal & 0.023 & 0.352 & 0.328 & 0.432 & 0.717 & 0.672 & 0.989 & 0.233 & 0.974 & 279 \\
\hline 21 & USA & 0.029 & 0.344 & 0.314 & 0.786 & 0.741 & 0.799 & 1.000 & 0.186 & 0.979 & 67 \\
\hline 22 & Belgium & 0.036 & 0.278 & 0.241 & 0.732 & 0.751 & 0.710 & 0.991 & 0.324 & 0.979 & 130 \\
\hline 23 & Venezuela & 0.040 & 0.250 & 0.210 & 0.873 & 0.686 & 0.614 & 0.999 & 0.152 & 0.980 & 441 \\
\hline 24 & Dom. Rep. & 0.047 & 0.292 & 0.245 & 0.559 & 0.677 & 0.652 & 1.000 & 0.087 & 0.971 & 121 \\
\hline 25 & Japan & 0.048 & 0.333 & 0.286 & 0.305 & 0.652 & 0.572 & 0.986 & 0.072 & 0.980 & 13 \\
\hline 26 & Ireland & 0.048 & 0.333 & 0.286 & 0.957 & 0.777 & 0.741 & 1.000 & 0.398 & 0.970 & 20 \\
\hline 27 & Argentina & 0.068 & 0.349 & 0.281 & 0.671 & 0.719 & 0.602 & 0.995 & 0.298 & 0.980 & 319 \\
\hline 28 & Brazil & 0.074 & 0.306 & 0.232 & 0.599 & 0.665 & 0.643 & 0.990 & 0.049 & 0.980 & 167 \\
\hline 29 & Angola & 0.086 & 0.286 & 0.200 & & 0.671 & 0.630 & 0.785 & 0.290 & 0.980 & 12 \\
\hline 30 & UK & 0.097 & 0.287 & 0.190 & 0.930 & 0.746 & 0.721 & 1.000 & 0.293 & 0.970 & 271 \\
\hline 31 & Canada & 0.104 & 0.286 & 0.182 & 0.756 & 0.737 & 0.777 & 0.998 & 0.196 & 0.978 & 18 \\
\hline 32 & Germany & 0.113 & 0.292 & 0.179 & 0.845 & 0.753 & 0.714 & 0.994 & 0.325 & 0.978 & 520 \\
\hline 33 & Netherlands & 0.114 & 0.354 & 0.240 & 0.881 & 0.744 & 0.723 & 0.997 & 0.288 & 0.970 & 98 \\
\hline 34 & France & 0.131 & 0.354 & 0.222 & 0.816 & 0.702 & 0.661 & 1.000 & 0.169 & 0.980 & 990 \\
\hline 35 & Iran & 0.132 & 0.286 & 0.154 & 0.063 & 0.593 & 0.426 & 0.959 & 0.016 & 0.971 & 20 \\
\hline 36 & Peru & 0.151 & 0.378 & 0.227 & 0.339 & 0.689 & 0.620 & 0.980 & 0.193 & 0.966 & 140 \\
\hline 37 & Lebanon & 0.167 & 0.167 & 0.000 & 0.679 & 0.608 & 0.448 & 0.977 & 0.028 & 0.980 & 11 \\
\hline 38 & Italy & 0.170 & 0.442 & 0.273 & 0.667 & 0.677 & 0.589 & 0.995 & 0.152 & 0.970 & 107 \\
\hline 39 & Cuba & 0.177 & 0.300 & 0.123 & 0.400 & 0.725 & 0.609 & 1.000 & 0.318 & 0.974 & 107 \\
\hline 40 & Finland & 0.179 & 0.429 & 0.250 & 0.783 & 0.826 & 0.757 & 0.999 & 0.569 & 0.980 & 11 \\
\hline 41 & Chile & 0.184 & 0.380 & 0.196 & 0.895 & 0.701 & 0.534 & 0.996 & 0.296 & 0.980 & 101 \\
\hline 42 & Colombia & 0.198 & 0.370 & 0.172 & 0.404 & 0.693 & 0.694 & 0.996 & 0.102 & 0.979 & 118 \\
\hline 43 & Denmark & 0.262 & 0.429 & 0.167 & 0.893 & 0.772 & 0.744 & 1.000 & 0.370 & 0.974 & 13 \\
\hline 44 & Sweden & 0.267 & 0.455 & 0.188 & 1.029 & 0.802 & 0.770 & 0.996 & 0.471 & 0.973 & 38 \\
\hline 45 & Romania & 0.375 & 0.375 & 0.000 & 0.577 & 0.683 & 0.708 & 0.989 & 0.056 & 0.977 & 15 \\
\hline & Mean & 0.055 & 0.270 & 0.215 & 0.569 & 0.687 & 0.613 & 0.968 & 0.191 & 0.975 & 6,110 \\
\hline & St. Dev. & 0.430 & 0.444 & 0.411 & 0.324 & 0.061 & 0.114 & 0.055 & 0.102 & 0.007 & \\
\hline
\end{tabular}

Notes: This Table displays the means of the smoking gender gap, the female smoking rate and the male smoking rate of our sample of ESTUDES second-generation immigrants living in Spain by country of ancestry (columns 1-3), as well as the mean values of the following country-of-ancestry variables: the female-to-male smoking ratio, the gender gap index and its four components (columns 4-9). Countries are ordered by the gender smoking gap in Spain. Column 10 displays our ESTUDES sample sizes of second-generation immigrants by country of ancestry. The last two rows display the overall cross-country means and standard deviations. 
Table 2. Cross-Correlations: Youth Gender Smoking Gap in Spain, Female-to-Male Smoking Ratio, and Gender Equality by Country of Ancestry

\begin{tabular}{|c|c|c|c|c|c|c|c|}
\hline & \multicolumn{2}{|l|}{ In Spain } & \multicolumn{4}{|c|}{ In Country of Ancestry } & \multirow[b]{2}{*}{$\begin{array}{l}\text { GGI } \\
\text { H\&S }\end{array}$} \\
\hline & $\begin{array}{l}\text { Smoking } \\
\text { gap in } \\
\text { Spain }\end{array}$ & $\begin{array}{c}\mathrm{F} / \mathrm{M} \\
\text { smoking } \\
\text { ratio }\end{array}$ & GGI & $\begin{array}{l}\text { GGI } \\
\text { Ec. } \\
\text { Opp }\end{array}$ & $\begin{array}{l}\text { GGI } \\
\text { Educ. }\end{array}$ & $\begin{array}{l}\text { GGI } \\
\text { Pol. }\end{array}$ & \\
\hline Smoking gap & 1 & & & & & & \\
\hline F/M smoking & 0.217 & 1 & & & & & \\
\hline GGI & 0.171 & 0.689 & 1 & & & & \\
\hline GGI Ec. Opp. & 0.122 & 0.521 & 0.854 & 1 & & & \\
\hline GGI Educ. & 0.277 & 0.616 & 0.495 & 0.344 & 1 & & \\
\hline GGI Pol. Emp. & 0.074 & 0.547 & 0.848 & 0.525 & 0.169 & 1 & \\
\hline GGI H\&S & 0.192 & 0.345 & 0.165 & 0.192 & 0.234 & -0.04 & 1 \\
\hline
\end{tabular}

Notes: This table displays Pearson correlations between variables.

Figure 1. Raw Female-to-Male Smoking Ratios of Second Generation Immigrants and Gender Equality in Countries of Ancestry

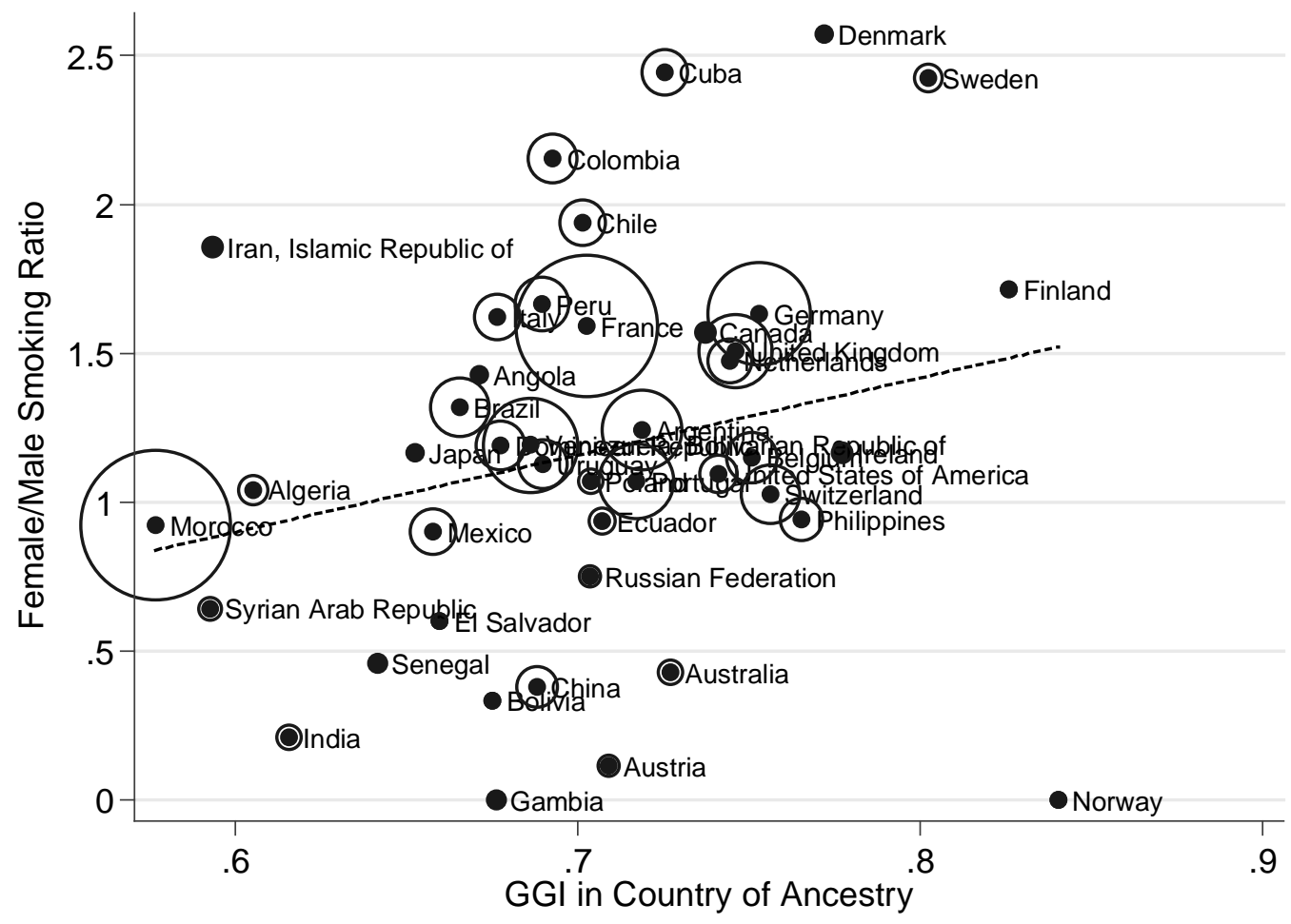

Notes: Figure 1 displays the correlation between the raw female-to-male smoking ratio among second-generation immigrants and the non-standardized GGI in the country of ancestry. The regression line has a slope of 3.142 with a standard error of 0.926 . The adjusted $\mathrm{R}^{2}$ is 0.20 . The bubbles represent the number of individuals in our sample. 
Table 3. The Effect of Gender Social Norms on the Youth Smoking Gender Gap

Using Alternative Measures of Gender Equality in the Country-of-Ancestry

Dependent Variable: Youth Smoking Dummy

\begin{tabular}{|c|c|c|c|c|c|c|c|}
\hline & (1) & (2) & (3) & (4) & (5) & (6) & (7) \\
\hline $\begin{array}{l}\text { Female-to-male } \\
\text { smoking ratio*Female } \\
\text { GGI*Female }\end{array}$ & $\begin{array}{l}0.046^{* * *} \\
(0.012)\end{array}$ & $\begin{array}{l}0.039^{* * *} \\
(0.008)\end{array}$ & & & & & \\
\hline GGI Ec. Opp.*Female & & & $\begin{array}{c}0.036^{* * *} \\
(0.009)\end{array}$ & & & & $\begin{array}{l}-0.005 \\
(0.021)\end{array}$ \\
\hline GGI Educ.*Female & & & & $\begin{array}{c}0.046^{* * *} \\
(0.013)\end{array}$ & & & $\begin{array}{l}0.039^{* *} \\
(0.019)\end{array}$ \\
\hline GGI Pol. Emp.*Female & & & & & $\begin{array}{l}0.024^{* *} \\
(0.010)\end{array}$ & & $\begin{array}{c}0.006 \\
(0.013)\end{array}$ \\
\hline $\begin{array}{l}\text { GGI Health and } \\
\text { Survival*Female }\end{array}$ & & & & & & $\begin{array}{l}0.033^{* * *} \\
(0.010)\end{array}$ & $\begin{array}{l}0.021^{* *} \\
(0.009)\end{array}$ \\
\hline$R^{2}$ & 0.088 & 0.087 & 0.086 & 0.088 & 0.085 & 0.087 & 0.090 \\
\hline Countries of ancestry & 46 & 45 & 45 & 45 & 45 & 45 & 45 \\
\hline Observations & 6,136 & 6,110 & 6,110 & 6,110 & 6,110 & 6,110 & 6,110 \\
\hline
\end{tabular}

Notes: OLS coefficient estimates and their associated standard errors clustered by country of ancestry in parentheses.

Country-of-ancestry measures are standardized. All the regressions include the following controls: a female dummy, age, age squared, parental labor market status dummies, parental education dummies, and their interactions with the female dummy as well as year and province fixed effects. *** indicates significance at least the $1 \%$ level, ** at least the $5 \%$ level, * at least the $10 \%$ level. 
Table 4. The Effect of Gender Equality in the Country of Ancestry on the Youth Smoking Gender Gap: Sensitivity to the Addition of Individual Controls

Dependent Variable: Youth Smoking Dummy

\begin{tabular}{|c|c|c|c|c|c|c|c|c|}
\hline & (1) & $(2)$ & (3) & (4) & (5) & (6) & (7) & (8) \\
\hline \multirow[t]{2}{*}{ Female } & $0.059^{* * *}$ & $0.059^{* * *}$ & $0.063^{* * *}$ & -0.402 & -0.919 & -0.870 & -0.671 & -0.350 \\
\hline & (0.019) & $(0.014)$ & $(0.013)$ & (1.420) & (1.400) & (1.281) & (1.287) & (1.213) \\
\hline \multirow[t]{2}{*}{ GGI } & & -0.005 & -0.005 & -0.006 & -0.005 & -0.012 & -0.013 & -0.012 \\
\hline & & $(0.008)$ & $(0.007)$ & $(0.008)$ & $(0.009)$ & $(0.009)$ & $(0.009)$ & $(0.010)$ \\
\hline \multirow[t]{2}{*}{ GGI*Female } & & $0.036^{* * *}$ & $0.038^{* * *}$ & $0.039^{* * *}$ & $0.036^{* * *}$ & $0.035^{* * *}$ & $0.036^{* * *}$ & $0.025^{* *}$ \\
\hline & & $(0.007)$ & $(0.006)$ & $(0.008)$ & $(0.009)$ & $(0.010)$ & $(0.010)$ & $(0.009)$ \\
\hline \multirow[t]{2}{*}{ Age } & & & $0.237^{*}$ & $0.206^{*}$ & 0.194 & 0.138 & 0.148 & 0.070 \\
\hline & & & $(0.121)$ & $(0.116)$ & (0.123) & (0.119) & $(0.122)$ & (0.109) \\
\hline \multirow[t]{2}{*}{ Age squared } & & & -0.005 & -0.004 & -0.005 & -0.003 & -0.003 & -0.002 \\
\hline & & & $(0.004)$ & $(0.004)$ & $(0.004)$ & $(0.004)$ & $(0.004)$ & $(0.004)$ \\
\hline \multirow[t]{2}{*}{ Mother works } & & & $0.038^{* * *}$ & $0.045^{* * *}$ & $0.043^{* * *}$ & $0.037^{* * *}$ & $0.038^{* * * *}$ & $0.034^{* * *}$ \\
\hline & & & $(0.013)$ & $(0.014)$ & $(0.014)$ & $(0.012)$ & $(0.012)$ & $(0.012)$ \\
\hline \multirow[t]{2}{*}{ Father works } & & & $-0.039^{* * *}$ & $-0.046^{* * *}$ & $-0.034^{*}$ & -0.014 & -0.011 & 0.002 \\
\hline & & & $(0.014)$ & $(0.017)$ & $(0.017)$ & $(0.018)$ & $(0.018)$ & $(0.018)$ \\
\hline \multirow[t]{2}{*}{ Mother Educ. High } & & & 0.011 & 0.025 & $0.049^{* *}$ & $0.052^{* * *}$ & $0.052^{* * *}$ & $0.042^{* *}$ \\
\hline & & & $(0.016)$ & $(0.022)$ & $(0.020)$ & $(0.019)$ & $(0.019)$ & $(0.018)$ \\
\hline \multirow[t]{2}{*}{ Mother Educ. Medium } & & & 0.015 & 0.005 & 0.015 & 0.007 & 0.010 & 0.002 \\
\hline & & & $(0.014)$ & $(0.021)$ & $(0.019)$ & $(0.019)$ & $(0.018)$ & $(0.018)$ \\
\hline \multirow[t]{2}{*}{ Father Educ. High } & & & -0.015 & -0.020 & -0.012 & -0.004 & -0.006 & -0.010 \\
\hline & & & $(0.015)$ & $(0.022)$ & $(0.022)$ & $(0.020)$ & $(0.019)$ & $(0.021)$ \\
\hline \multirow[t]{2}{*}{ Father Educ. Medium } & & & -0.005 & 0.000 & 0.001 & -0.002 & -0.002 & 0.000 \\
\hline & & & $(0.011)$ & $(0.014)$ & $(0.012)$ & $(0.013)$ & $(0.012)$ & $(0.012)$ \\
\hline \multirow[t]{2}{*}{ Age*Female } & & & & 0.066 & 0.132 & 0.125 & 0.099 & 0.051 \\
\hline & & & & $(0.182)$ & $(0.178)$ & $(0.163)$ & $(0.164)$ & $(0.156)$ \\
\hline \multirow[t]{2}{*}{ Age squared*Female } & & & & -0.002 & -0.004 & -0.004 & -0.003 & -0.002 \\
\hline & & & & $(0.006)$ & $(0.006)$ & $(0.005)$ & $(0.005)$ & $(0.005)$ \\
\hline \multirow[t]{2}{*}{ Mother works*Female } & & & & -0.013 & -0.011 & -0.012 & -0.012 & -0.018 \\
\hline & & & & $(0.020)$ & $(0.019)$ & $(0.020)$ & $(0.020)$ & $(0.021)$ \\
\hline \multirow[t]{2}{*}{ Father works*Female } & & & & 0.013 & 0.017 & 0.008 & 0.006 & -0.010 \\
\hline & & & & $(0.022)$ & $(0.021)$ & $(0.025)$ & $(0.026)$ & $(0.026)$ \\
\hline Mother Educ. & & & & -0.027 & -0.036 & -0.031 & -0.032 & -0.038 \\
\hline High*Female & & & & $(0.038)$ & $(0.033)$ & $(0.032)$ & $(0.032)$ & $(0.029)$ \\
\hline Mother Educ. & & & & 0.021 & 0.018 & 0.020 & 0.016 & 0.022 \\
\hline Medium*Female & & & & $(0.032)$ & $(0.029)$ & $(0.030)$ & $(0.030)$ & $(0.026)$ \\
\hline Father Educ. & & & & 0.013 & 0.018 & 0.023 & 0.024 & 0.032 \\
\hline High*Female & & & & $(0.035)$ & $(0.032)$ & $(0.030)$ & $(0.030)$ & $(0.026)$ \\
\hline Father Educ. & & & & -0.012 & -0.003 & 0.000 & -0.000 & 0.005 \\
\hline Medium*Female & & & & $(0.024)$ & $(0.021)$ & $(0.020)$ & $(0.021)$ & $(0.020)$ \\
\hline \multirow[t]{2}{*}{ Works } & & & & & $0.107^{* * *}$ & $0.104^{* * *}$ & $0.097^{* * *}$ & $0.078^{* * *}$ \\
\hline & & & & & $(0.031)$ & $(0.029)$ & $(0.029)$ & $(0.024)$ \\
\hline \multirow[t]{2}{*}{ Works*Female } & & & & & 0.007 & -0.001 & -0.004 & -0.015 \\
\hline & & & & & $(0.028)$ & $(0.027)$ & $(0.030)$ & $(0.027)$ \\
\hline \multirow[t]{2}{*}{ Grade Retention } & & & & & $0.129^{* * *}$ & $0.112^{* * *}$ & $0.107^{* * *}$ & $0.104^{* * *}$ \\
\hline & & & & & $(0.018)$ & $(0.019)$ & $(0.019)$ & $(0.018)$ \\
\hline Grade & & & & & 0.013 & 0.019 & 0.016 & 0.002 \\
\hline Retention*Female & & & & & $(0.037)$ & $(0.037)$ & $(0.038)$ & $(0.035)$ \\
\hline Lives with Mother and & & & & & & $-0.084^{* * *}$ & $-0.079^{* * *}$ & $-0.063^{* * *}$ \\
\hline Father & & & & & & $(0.022)$ & $(0.023)$ & $(0.021)$ \\
\hline
\end{tabular}


Lives with Mother and

$\begin{array}{lll}0.024 & 0.024 & 0.033\end{array}$

Father*Female

(0.033)

(0.034)

(0.030)

Cohabiting Mother

$0.117^{* * *}$

$0.105^{* * *}$

$0.084^{* * *}$

Smokes

(0.022)

(0.022)

(0.022)

Cohabiting Mother

Smokes*Female

(0.029)

(0.028)

$0.077^{* * *}$

$0.065^{* * *}$

(0.027)

Cohabiting Father

(0.022)

(0.021)

$0.049^{* *}$

Smokes

$-0.017 \quad-0.023$

(0.019)

Cohabiting Father

(0.023)

(0.024)

$0.161^{* * *}$

$-0.019$

Cohabiting Siblings

(0.038)

(0.025)

Smoke

0.024

$0.126^{*}$

Cohabiting Siblings

(0.039)

(0.037)

Smoke*Female

Students Smoke in

(0.047)

School

0.013

0.015

Students Smoke in

(0.020)

(0.016)

School*Female

All/most/some Friends

$-0.004$

Smoke

(0.019)

$0.260^{* * *}$

All/most/some Friends

(0.016)

$0.077^{* * *}$

Smoke*Female

\begin{tabular}{lllllllll}
\hline$R^{2}$ & 0.047 & 0.049 & 0.086 & 0.087 & 0.111 & 0.135 & 0.148 & 0.252 \\
Observations & 6,110 & 6,110 & 6,110 & 6,110 & 6,110 & 6,110 & 6,110 & 6,110
\end{tabular}

Notes: OLS coefficient estimates and their associated standard errors clustered at the province level in parentheses. GGI is standardized. All the regressions include year and province fixed effects.

$* * *$ indicates significance at least the $1 \%$ level, ** at least the $5 \%$ level, * at least the $10 \%$ level. 
Table 5. Additional Robustness Checks

Dependent Variable: Youth Smoking Dummy

\begin{tabular}{|c|c|c|c|c|c|c|c|c|}
\hline & (1) & $(2)$ & (3) & (4) & (5) & (6) & (7) & (8) \\
\hline GGI*Female & $\begin{array}{c}0.039^{* * *} \\
(0.008)\end{array}$ & $\begin{array}{l}0.039^{* * *} \\
(0.008)\end{array}$ & $\begin{array}{c}0.039^{* * *} \\
(0.009)\end{array}$ & $\begin{array}{c}0.040^{* * *} \\
(0.009)\end{array}$ & $\begin{array}{l}0.039^{* *} \\
(0.015)\end{array}$ & $\begin{array}{l}0.025^{* *} \\
(0.011)\end{array}$ & $\begin{array}{l}0.024^{* *} \\
(0.009)\end{array}$ & $\begin{array}{l}0.036^{* * *} \\
(0.008)\end{array}$ \\
\hline Gini & & $\begin{array}{c}0.001 \\
(0.008)\end{array}$ & & & & & & \\
\hline Gini*Female & & $\begin{array}{c}-0.001 \\
(0.014)\end{array}$ & & & & & & \\
\hline Spanish speaking & & & -0.001 & & & & & \\
\hline country & & & $(0.021)$ & & & & & \\
\hline Spanish*Female & & & $\begin{array}{c}0.012 \\
(0.024)\end{array}$ & & & & & \\
\hline GGI & Yes & Yes & Yes & Yes & Yes & Yes & Yes & No \\
\hline Province FE & Yes & Yes & Yes & Yes & Yes & Yes & No & Yes \\
\hline Country of Ancestry FE & No & No & No & No & No & No & No & Yes \\
\hline Year FE & Yes & Yes & Yes & Yes & Yes & Yes & Yes & Yes \\
\hline Year FE*Female & No & No & No & Yes & No & No & No & No \\
\hline CCAA FE & No & No & No & No & No & No & Yes & No \\
\hline CCAA FE*Female & No & No & No & No & No & Yes & Yes & No \\
\hline$R^{2}$ & 0.087 & 0.087 & 0.087 & 0.087 & 0.087 & 0.091 & 0.085 & 0.096 \\
\hline Observations & 6,110 & 6,099 & 6,110 & 6,110 & 6,110 & 6,110 & 6,110 & 6,110 \\
\hline
\end{tabular}

Notes: All country-of-ancestry variables are standardized. OLS coefficient estimates and their associated standard errors clustered by country of ancestry in parentheses, with the exception of Column 5, where they are clustered by students' province of residence. On top of the variables indicated in the table, all the regressions include the following controls: a female dummy, age, age squared, parental labor market status dummies, parental education dummies, and their interactions with the female dummy as well as year fixed effects. *** indicates significance at least the $1 \%$ level, ** at least the $5 \%$ level, * at least the $10 \%$ level. 
Table 6. Sensitivity to Changes in Sample Criteria

Dependent Variable: Youth Smoking Dummy

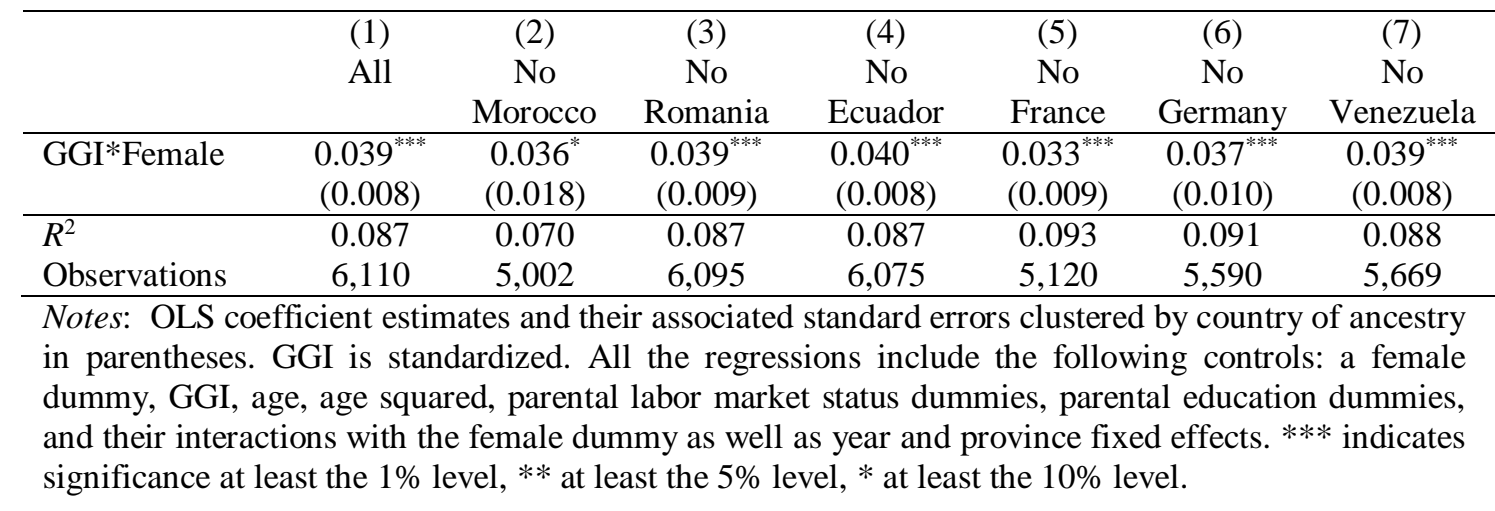


Table 7. Subgroup Analyses

\begin{tabular}{|c|c|c|c|}
\hline A. By Maternal Education & $<$ Secondary Education & $\begin{array}{l}\geq \text { Secondary } \\
\text { Education }\end{array}$ & $\begin{array}{l}\text { Test of Equality of } \\
\text { Coefficients (p- } \\
\text { value) }\end{array}$ \\
\hline GGI*Female & $\begin{array}{c}0.053^{* * *} \\
(0.011)\end{array}$ & $\begin{array}{c}0.018 \\
(0.012)\end{array}$ & {$[0.039]^{* *}$} \\
\hline $\mathrm{R}^{2}$ & 0.138 & 0.077 & \\
\hline $\mathrm{N}$ & 2,524 & 3,586 & \\
\hline B. By Maternal Work Status & Working & Not Working & $\begin{array}{c}\text { Test of Equality of } \\
\text { Coefficients (p- } \\
\text { value) }\end{array}$ \\
\hline GGI×Female & $\begin{array}{c}0.036^{* * *} \\
(0.012)\end{array}$ & $\begin{array}{c}0.037^{* * *} \\
(0.013)\end{array}$ & {$[0.982]$} \\
\hline $\mathrm{R}^{2}$ & 0.077 & 0.128 & \\
\hline C. By Family Structure & Lives with Both Parents & $\begin{array}{l}\text { Does not Live with } \\
\text { Both Parents }\end{array}$ & $\begin{array}{c}\text { Test of Equality of } \\
\text { Coefficients (p- } \\
\text { value) }\end{array}$ \\
\hline $\begin{array}{l}R^{2} \\
\mathrm{~N}\end{array}$ & $\begin{array}{c}0.039^{* * *} \\
(0.009) \\
0.091 \\
4,814 \\
\end{array}$ & $\begin{array}{c}0.038^{*} \\
(0.021) \\
0.111 \\
1,296 \\
\end{array}$ & [0.959] \\
\hline $\begin{array}{l}\text { D. By Smoking Habits of } \\
\text { Cohabitating Siblings }\end{array}$ & $\begin{array}{l}\text { Cohabiting Siblings } \\
\text { Smoke }\end{array}$ & $\begin{array}{c}\text { Cohabiting Siblings do } \\
\text { not Smoke }\end{array}$ & $\begin{array}{c}\text { Test of Equality of } \\
\text { Coefficients (p- } \\
\text { value) }\end{array}$ \\
\hline $\begin{array}{l}\text { GGI*Female } \\
R^{2} \\
\mathrm{~N}\end{array}$ & $\begin{array}{c}0.071^{* * *} \\
(0.026) \\
0.274 \\
453\end{array}$ & $\begin{array}{c}0.035^{* * *} \\
(0.009) \\
0.083 \\
5,657\end{array}$ & {$[0.107]$} \\
\hline E. By Friends’ Smoking Habits & $\begin{array}{l}\text { All/most/some Friends } \\
\text { Smoke }\end{array}$ & $\begin{array}{l}\text { Few/no Friends } \\
\text { Smoke }\end{array}$ & $\begin{array}{c}\text { Test of Equality of } \\
\text { Coefficients (p- } \\
\text { value) }\end{array}$ \\
\hline GGI×Female & $\begin{array}{c}0.048^{* * * *} \\
(0.013) \\
0.054 \\
3,129\end{array}$ & $\begin{array}{c}0.013^{* *} \\
(0.006) \\
0.058 \\
2,981\end{array}$ & {$[0.019]^{* *}$} \\
\hline $\begin{array}{l}\text { F. By Proportion of Immigrants of } \\
\text { Same Ancestry }\end{array}$ & Above Median & Below Median & $\begin{array}{c}\text { Test of Equality of } \\
\text { Coefficients (p- } \\
\text { value) } \\
\end{array}$ \\
\hline GGI×Female & $\begin{array}{l}0.035^{* * * *} \\
(0.009)\end{array}$ & $\begin{array}{l}0.072^{* * * *} \\
(0.024)\end{array}$ & {$[0.133]$} \\
\hline$R^{2}$ & 0.086 & 0.129 & \\
\hline
\end{tabular}


Table 8. The Effect of Country-of-Ancestry Gender Equality on the Gender Gap in Other Risky Behaviors

\begin{tabular}{|c|c|c|c|c|c|c|}
\hline & $\begin{array}{c}(1) \\
\text { Consumed } \\
\text { alcohol }\end{array}$ & $\begin{array}{c}\text { (2) } \\
\text { Got drunk }\end{array}$ & $\begin{array}{l}(3) \\
\text { Binge } \\
\text { drank }\end{array}$ & $\begin{array}{c}(4) \\
\text { Smoked } \\
\text { marijuana }\end{array}$ & $\begin{array}{c}(5) \\
\text { Involved in } \\
\text { a fight }\end{array}$ & $\begin{array}{c}(6) \\
\text { Arrested }\end{array}$ \\
\hline GGI*Female & $\begin{array}{c}0.048^{* * *} \\
(0.011)\end{array}$ & $\begin{array}{l}0.035^{* * *} \\
(0.010)\end{array}$ & $\begin{array}{l}0.019^{*} \\
(0.010)\end{array}$ & $\begin{array}{l}0.022^{* *} \\
(0.009)\end{array}$ & $\begin{array}{c}0.031^{* * *} \\
(0.011)\end{array}$ & $\begin{array}{r}0.005 \\
(0.007) \\
\end{array}$ \\
\hline $\begin{array}{l}R^{2} \\
N\end{array}$ & $\begin{array}{l}0.213 \\
6,130\end{array}$ & $\begin{array}{l}0.115 \\
6,075\end{array}$ & $\begin{array}{l}0.138 \\
6,111\end{array}$ & $\begin{array}{l}0.079 \\
6,124\end{array}$ & $\begin{array}{l}0.066 \\
6,130\end{array}$ & $\begin{array}{l}0.063 \\
6,134\end{array}$ \\
\hline \multicolumn{7}{|c|}{$\begin{array}{l}\text { Notes: OLS coefficient estimates and their associated standard errors clustered by country of ancestry in } \\
\text { parentheses. GGI is standardized. All the regressions include the following controls: a female dummy, } \\
\text { GGI, age, age squared, parental labor market status dummies, parental education dummies, and their } \\
\text { interactions with the female dummy as well as year and province fixed effects. Dependent variables } 1-4 \\
\text { refer to the previous month, while dependent variables } 5-6 \text { refer to the previous year. Binge drinking is } \\
\text { defined as ingesting } 5+\text { alcoholic drinks in no more than } 2 \text { hours. }{ }^{* * *} \text { indicates significance at least the } 1 \% \\
\text { level, ** at least the } 5 \% \text { level, * at least the } 10 \% \text { level }\end{array}$} \\
\hline
\end{tabular}


Table 9. Gender Differences in Perceived Risks of Smoking, Information on Drugs, Parental Discipline and

Access to Tobacco

Panel A. Beliefs About the Health Effects of Smoking

Smoking sometimes creates several or many health problems

(2) (3)

(3) (4)

Smoking 1 pack a day creates several Smoking sometimes creates Smoking 1 pack a day creates many or many health problems many health problems health problems

\begin{tabular}{|c|c|c|c|c|c|c|c|c|c|}
\hline & \multicolumn{3}{|c|}{ several or many health problems } & \multicolumn{2}{|c|}{ or many health problems } & \multicolumn{2}{|c|}{ many health problems } & \multicolumn{2}{|c|}{ health problems } \\
\hline Female & \multicolumn{2}{|c|}{$\begin{array}{c}0.001 \\
(0.013)\end{array}$} & \multicolumn{3}{|c|}{$0.058^{* * *}$} & \multicolumn{2}{|c|}{$\begin{array}{l}-0.015^{*} \\
(0.008)\end{array}$} & \multicolumn{2}{|c|}{$0.081^{* * *}$} \\
\hline$R^{2}$ & \multicolumn{2}{|r|}{$\frac{(0.013)}{0.042}$} & \multicolumn{3}{|c|}{$\frac{(0.011)}{0.038}$} & \multicolumn{2}{|l|}{0.041} & \multicolumn{2}{|c|}{0.028} \\
\hline$N$ & \multicolumn{2}{|c|}{6,083} & \multicolumn{3}{|c|}{6,051} & 6,083 & & 6,0 & \\
\hline \multicolumn{10}{|c|}{ Panel B. Information on Drugs. Amount (self-assessed) and Sources } \\
\hline & $(1)$ & $(2)$ & $(3)$ & $(4)$ & (5) & (6) & (7) & (8) & (9) \\
\hline & $\begin{array}{c}\text { Full } \\
\text { informed } \\
\text { about drugs }\end{array}$ & $\begin{array}{l}\text { Mother is one } \\
\text { of main info } \\
\text { sources on } \\
\text { drugs }\end{array}$ & $\begin{array}{c}\text { Father is one } \\
\text { of main info } \\
\text { sources on } \\
\text { drugs }\end{array}$ & $\begin{array}{l}\text { Siblings are } \\
\text { one of main } \\
\text { info sources } \\
\text { on drugs }\end{array}$ & $\begin{array}{l}\text { Friends are } \\
\text { one of main } \\
\text { info sources } \\
\text { on drugs }\end{array}$ & $\begin{array}{l}\text { Teachers are } \\
\text { one of main } \\
\text { info sources } \\
\text { on drugs }\end{array}$ & $\begin{array}{l}\text { Health prof. } \\
\text { are one of } \\
\text { main info } \\
\text { sources on } \\
\text { drugs }\end{array}$ & $\begin{array}{l}\text { Internet is one } \\
\text { of main info } \\
\text { sources on } \\
\text { drugs }\end{array}$ & $\begin{array}{c}\text { Dr. asked } \\
\text { about tobacco } \\
\text { consumption }\end{array}$ \\
\hline Female & $\begin{array}{l}-0.107^{* * *} \\
(0.015)\end{array}$ & $\begin{array}{c}0.003 \\
(0.012)\end{array}$ & $\begin{array}{l}-0.026^{* *} \\
(0.012)\end{array}$ & $\begin{array}{c}0.010 \\
(0.007)\end{array}$ & $\begin{array}{c}0.013 \\
(0.009)\end{array}$ & $\begin{array}{l}0.050^{* * *} \\
(0.013)\end{array}$ & $\begin{array}{c}0.018^{*} \\
(0.010)\end{array}$ & $\begin{array}{c}0.010 \\
(0.010)\end{array}$ & $\begin{array}{l}0.029^{* *} \\
(0.012)\end{array}$ \\
\hline$R^{2}$ & 0.051 & 0.025 & 0.380 & 0.107 & 0.270 & 0.386 & 0.215 & 0.258 & 0.093 \\
\hline$N$ & 6,051 & 6,193 & 6,193 & 6,193 & 6,193 & 6,193 & 6,193 & 6,193 & 6,024 \\
\hline
\end{tabular}

Panel C. Parental Rules and Monitoring Inside and Outside the Home

(1)

Parents almost always/often set

clear rules about what can be done at home

$-0.022$

\begin{tabular}{lc}
-0.022 \\
Female \\
$0.010)$ \\
\hline
\end{tabular}

(2)

Parents almost always/often set clear rules about what can be done
(3) (4)

Parents almost always/often know Parents almost always/often know who I go out with at night

\begin{tabular}{lrccc} 
& $(0.010)$ & $(0.012)$ & $(0.016)$ & $(0.017)$ \\
\hline$R^{2}$ & 0.056 & 0.058 & 0.024 & 0.033 \\
$N$ & 6,068 & 6,045 & 5,982 & 5,975 \\
\hline
\end{tabular}

Panel D. Parental Rules Regarding their Children Smoking Habits and Access to Tobacco

$$
\text { (1) }
$$

Mother allows/would

allow student to smoke

$$
\text { anywhere }
$$$$
-0.006
$$

(0.008)

0.060

5,966

(2)

Mother allows/would allow

(3)

Father allows/would allow student to smoke anywhere

(5)

$\begin{array}{lc}\text { Father allows/would allow } & \text { Very easy access to } \\ \text { student to smoke anywhere } & \text { tobacco }\end{array}$ student to smoke any
home

home

0.001

$(0.010)$

0.110
5,966

-0.008
$(0.006)$
0.041
5,964

but home

$\begin{array}{ll}-0.009 & 0.029^{* *}\end{array}$

$(0.009) \quad(0.012)$

$0.085 \quad 0.098$

controls: age, age squared, parental labor market status dummies, parental education dummies, year and province fixed effects.

*** indicates significance at least the $1 \%$ level, ** at least the $5 \%$ level, * at least the $10 \%$ level. 
Table 10. The Effect of Gender Equality in the Country of Ancestry on the Gender Gap in Perceived Risks of Smoking,

\section{Information on Drugs, Parental Discipline and Access to Tobacco}

\section{Panel A. Beliefs About the Health Effects of Smoking}

Smoking sometimes creates several or many health problems

\begin{tabular}{lcccc} 
& or many health problems & several or many health problems & many health problems & many health problems \\
\hline GGI ${ }^{*}$ & 0.021 & 0.005 & 0.005 & -0.013 \\
Female & $(0.013)$ & $(0.010)$ & $(0.006)$ & $(0.011)$ \\
\hline$R^{2}$ & 0.043 & 0.040 & 0.043 & 0.030 \\
$N$ & 6,083 & 6,051 & 6,083 & 6,051 \\
\hline
\end{tabular}

Panel B. Information on Drugs. Amount (self-assessed) and Sources$$
\text { (1) }
$$

Perfectly

(2)

informed

about drugs

(3)

Mother is one

of main info

Father is one

of main info

(4)

sources on

sources on

Siblings are

one of main

(5)

info sources

Friends are

one of main

(6)

Teachers are

one of main

info sources

info sources

on drugs

on drugs

\section{(7)}

Health prof.

are one of

main info

sources on

\begin{tabular}{|c|c|c|c|c|c|c|c|c|c|}
\hline & & & & & & & drugs & & \\
\hline GGI * & -0.002 & 0.010 & $0.027^{* * *}$ & -0.008 & $0.011^{* *}$ & -0.007 & 0.002 & $-0.016^{* *}$ & 0.005 \\
\hline Female & $(0.007)$ & $(0.009)$ & $(0.007)$ & $(0.006)$ & $(0.004)$ & $(0.011)$ & $(0.005)$ & $(0.006)$ & $(0.011)$ \\
\hline$R^{2}$ & 0.054 & 0.028 & 0.382 & 0.108 & 0.272 & 0.388 & 0.216 & 0.260 & 0.095 \\
\hline$N$ & 6,051 & 6,193 & 6,193 & 6,193 & 6,193 & 6,193 & 6,193 & 6,193 & 6,024 \\
\hline
\end{tabular}

Panel C. Parental Rules and Monitoring Inside and Outside the Home

Parents almost always/often set

clear rules about what can be done at home

\begin{tabular}{l} 
GGI * \\
Female \\
\hline$R^{2}$ \\
$N$ \\
\hline
\end{tabular}

(2)

Parents almost always/often set clear rules about what can be done out of home

Parents almost always/often know who I go out with at night

\begin{tabular}{cccc} 
at home & home & night & \\
0.018 & -0.014 & $-0.022^{* * *}$ & $-0.027^{* *}$ \\
$(0.011)$ & $(0.009)$ & $(0.007)$ & $(0.011)$ \\
0.058 & 0.062 & 0.025 & 0.036 \\
6,068 & 6,045 & 5,982 & 5,975 \\
\hline
\end{tabular}

\section{Panel D. Parental Rules Regarding their Children Smoking Habits and Access to Tobacco}

$$
\text { (1) }
$$

$\begin{array}{ccc}(1) & (2) & (3) \\ \text { Mother allows/would allow } & \text { Mother allows/would allow student } & \text { Father allows/would }\end{array}$ student to smoke anywhere to smoke anywhere but home

allow student to smoke

(4)

Father allows/would allow Very easy access student to smoke anywhere but to tobacco anywhere

\begin{tabular}{lcccc} 
& & anywhere & home \\
\hline GGI ${ }^{*}$ & 0.004 & $0.013^{*}$ & 0.001 & 0.004 \\
Female & $(0.006)$ & $(0.007)$ & $(0.004)$ & $(0.006)$ \\
\hline$R^{2}$ & 0.062 & 0.116 & 0.043 & $0.033^{* *}$ \\
$N$ & 5,966 & 5,966 & 5,964 & $0.013)$ \\
\hline
\end{tabular}

S coefficient estimates and their associated standard errors clustered by country of ancestry in parentheses. All the regressions include the following controls: a female dummy, standardiz GGI, age, age squared, parental labor market status dummies, parental education dummies, and their interactions with the female dummy as well as year and province fixed effects. *** indicates significance at least the $1 \%$ level, ** at least the $5 \%$ level, * at least the $10 \%$ level. 


\section{Appendix}

Table A. 1. Individual-Level Variables: Descriptive Statistics

\begin{tabular}{lcccc}
\hline \hline Variables & $\begin{array}{c}(1) \\
\text { Mean }\end{array}$ & $\begin{array}{c}(2) \\
\text { St. Dev. }\end{array}$ & $\begin{array}{c}(3) \\
\text { Min. }\end{array}$ & $\begin{array}{c}(4) \\
\text { Max. }\end{array}$ \\
\hline Youth Smokes & & & & \\
Female & 0.244 & 0.430 & 0 & 1 \\
Age & 0.540 & 0.498 & 0 & 1 \\
Youth Works & 15.59 & 1.210 & 14 & 18 \\
Grade Retention & 0.135 & 0.341 & 0 & 1 \\
Lives with Mother and Father & 0.303 & 0.460 & 0 & 1 \\
Cohabiting Mother Smokes & 0.788 & 0.409 & 0 & 1 \\
Cohabiting Father Smokes & 0.218 & 0.413 & 0 & 1 \\
Cohabiting Siblings Smoke & 0.212 & 0.409 & 0 & 1 \\
Students Smoke in School & 0.074 & 0.262 & 0 & 1 \\
All/most Friends Smoke & 0.683 & 0.465 & 0 & 1 \\
Mother works & 0.281 & 0.450 & 0 & 1 \\
Father works & 0.594 & 0.491 & 0 & 1 \\
Mother Educ. High & 0.787 & 0.410 & 0 & 1 \\
Mother Educ. Medium & 0.243 & 0.429 & 0 & 1 \\
Father Educ. High & 0.344 & 0.475 & 0 & 1 \\
Father Educ. Medium & 0.238 & 0.426 & 0 & 1 \\
\hline \hline Notes: Statistics based on the benchmark sample of & 0.110 & 0 & 1 \\
immigrants used in most of our estimations. Source: ESTUDES 2006, 2008, 2010 and \\
2012.
\end{tabular}

Table A.2. Smoking Prevalence by Gender and Immigrant Status

\begin{tabular}{lcccc}
\hline \hline & All & Natives & $\begin{array}{c}\text { 2nd. Gen. } \\
\text { Imm. }\end{array}$ & $\begin{array}{c}\text { 2nd. Gen. } \\
\text { Imm. (final } \\
\text { sample) }\end{array}$ \\
\hline Girls & 0.297 & 0.305 & 0.270 & 0.271 \\
Boys & 0.247 & 0.250 & 0.216 & 0.215 \\
Gap & $\mathbf{0 . 0 4 9}$ & $\mathbf{0 . 0 5 5}$ & $\mathbf{0 . 0 5 4}$ & $\mathbf{0 . 0 5 5}$ \\
P-value & $(0.000)$ & $(0.000)$ & $(0.000)$ & $(0.000)$ \\
$\mathrm{N}$ & 114,381 & 96,209 & 6,903 & 6,110 \\
\hline \hline
\end{tabular}

Notes: Source: ESTUDES 2006, 2008, 2010 and 2012. 
Figure A.1. Raw Female-to-Male Smoking Ratios of Second Generation Immigrants and Female-to-Male Smoking Ratios in Countries of Ancestry

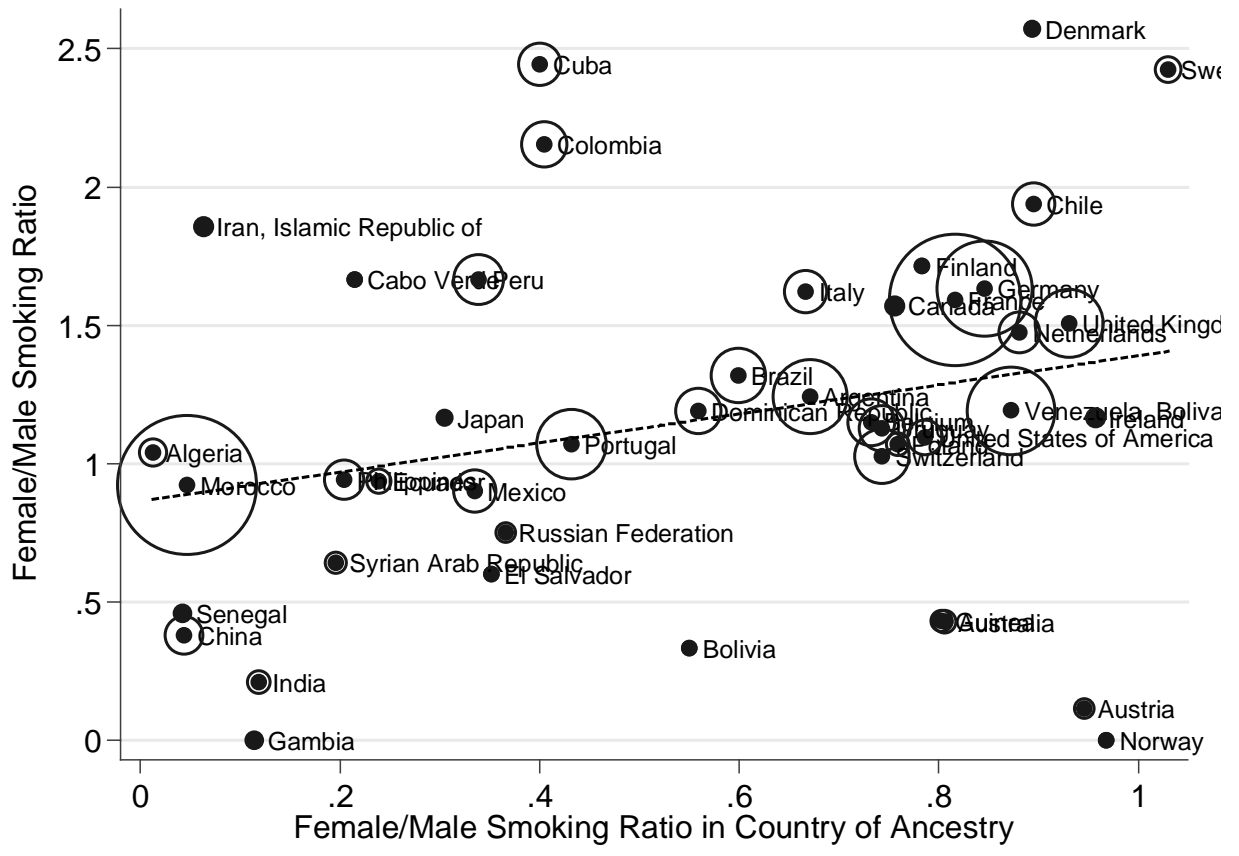

Notes: Appendix Figure A.1 displays the correlation between the raw female-to-male smoking ratio among secondgeneration immigrants and the female-to-male smoking ratio in the country of ancestry. The regression line has a slope of 0.647 with a standard error of 0.168 . The adjusted $R^{2}$ is 0.24 . The bubbles represent the number of individuals in our sample.

Table A.3. Logit Average Partial Effects. The Effect of Gender Social Norms on the Youth Smoking Gender Gap, Using Alternative Measures of Gender Equality in the Country-of-Ancestry.

Dependent Variable: Youth Smoking Dummy

\begin{tabular}{|c|c|c|c|c|c|c|c|}
\hline & $(1)$ & (2) & (3) & (4) & (5) & (6) & (7) \\
\hline $\begin{array}{l}\text { Female-to-male smoking } \\
\text { ratio*Female }\end{array}$ & $\begin{array}{l}0.044^{* * *} \\
(0.011)\end{array}$ & & & & & & \\
\hline GGI*Female & & $\begin{array}{l}0.037^{* * *} \\
(0.007)\end{array}$ & & & & & \\
\hline GGI Ec. Opp.*Female & & & $\begin{array}{l}0.033^{* * *} \\
(0.009)\end{array}$ & & & & $\begin{array}{l}-0.005 \\
(0.019)\end{array}$ \\
\hline GGI Educ.*Female & & & & $\begin{array}{l}0.050^{* * *} \\
(0.015)\end{array}$ & & & $\begin{array}{l}0.044^{* *} \\
(0.020)\end{array}$ \\
\hline GGI Pol. Emp.*Female & & & & & $\begin{array}{l}0.019^{* *} \\
(0.009)\end{array}$ & & $\begin{array}{c}0.004 \\
(0.011)\end{array}$ \\
\hline $\begin{array}{l}\text { GGI Health and } \\
\text { Survival*Female }\end{array}$ & & & & & & $\begin{array}{l}0.035^{* *} \\
(0.012)\end{array}$ & $\begin{array}{l}0.022^{* *} \\
(0.011)\end{array}$ \\
\hline Pseudo- $R^{2}$ & 0.087 & 0.086 & 0.086 & 0.088 & 0.085 & 0.087 & 0.089 \\
\hline Countries of ancestry & 46 & 45 & 45 & 45 & 45 & 45 & 45 \\
\hline Observations & 6,136 & 6,110 & 6,110 & 6,110 & 6,110 & 6,110 & 6,110 \\
\hline
\end{tabular}

Notes: Logit average partial effects and their associated standard errors clustered by country of ancestry in parentheses. All the regressions include the following controls: a female dummy, age, age squared, parental labor market status dummies, parental education dummies, and their interactions with the female dummy, as well as year and province fixed effects. *** indicates significance at least the $1 \%$ level, ** at least the $5 \%$ level, * at least the $10 \%$ level. 
Table A.4. Probit Average Partial Effects. The Effect of Gender Social Norms on Youth Smoking Gender Gap, Using Alternative Measures of Gender Equality in the Country-of-Ancestry Estimates

\section{Dependent Variable: Youth Smoking Dummy}

\begin{tabular}{|c|c|c|c|c|c|c|c|}
\hline & $(1)$ & (2) & (3) & (4) & (5) & (6) & (7) \\
\hline $\begin{array}{l}\text { Female-to-male smoking } \\
\text { ratio*Female }\end{array}$ & $\begin{array}{l}0.045^{* * *} \\
(0.011)\end{array}$ & & & & & & \\
\hline GGI*Female & & $\begin{array}{l}0.039^{* * *} \\
(0.007)\end{array}$ & & & & & \\
\hline GGI Ec. Opp.*Female & & & $\begin{array}{l}0.036^{* * * *} \\
(0.009)\end{array}$ & & & & $\begin{array}{l}-0.004 \\
(0.019)\end{array}$ \\
\hline GGI Educ.*Female & & & & $\begin{array}{l}0.050^{* * *} \\
(0.013)\end{array}$ & & & $\begin{array}{l}0.043^{* *} \\
(0.019)\end{array}$ \\
\hline GGI Pol. Emp.*Female & & & & & $\begin{array}{l}0.021^{* *} \\
(0.010)\end{array}$ & & $\begin{array}{c}0.004 \\
(0.011)\end{array}$ \\
\hline $\begin{array}{l}\text { GGI Health and } \\
\text { Survival*Female }\end{array}$ & & & & & & $\begin{array}{l}0.036^{* * *} \\
(0.011)\end{array}$ & $0.023^{* *}$ \\
\hline$\frac{\text { SurvivalFFemale }}{R^{2}}$ & 0.087 & 0.086 & 0.086 & 0.088 & 0.085 & 0.087 & $\frac{0.011)}{0.090}$ \\
\hline Countries of ancestry & 46 & 45 & 45 & 45 & 45 & 45 & 45 \\
\hline Observations & 6,136 & 6,110 & 6,110 & 6,110 & 6,110 & 6,110 & 6,110 \\
\hline
\end{tabular}

Notes: Probit average partial effects and their associated standard errors clustered by country of ancestry in parentheses. All the regressions include the following controls: a female dummy, age, age squared, parental labor market status dummies, parental education dummies, and their interactions with the female dummy as well as year and province fixed effects. *** indicates significance at least the $1 \%$ level, ** at least the $5 \%$ level, * at least the $10 \%$ level. 
Table A.5. Sensitivity Analysis to Individual Controls Using Country-of-Ancestry Female-to-Male Smoking Prevalence Ratio instead of the GGI

Dependent variable: Youth Smoking Dummy

\begin{tabular}{|c|c|c|c|c|c|c|c|c|}
\hline & $(1)$ & $(2)$ & (3) & $(4)$ & $(5)$ & (6) & (7) & $(8)$ \\
\hline Female & $\begin{array}{l}0.058^{* * *} \\
(0.019)\end{array}$ & $\begin{array}{l}0.058^{* * *} \\
(0.011)\end{array}$ & $\begin{array}{l}0.062^{* * *} \\
(0.011)\end{array}$ & $\begin{array}{l}-0.450 \\
(1.438)\end{array}$ & $\begin{array}{l}-0.954 \\
(1.411)\end{array}$ & $\begin{array}{l}-0.928 \\
(1.307)\end{array}$ & $\begin{array}{l}-0.726 \\
(1.316)\end{array}$ & $\begin{array}{l}-0.368 \\
(1.237)\end{array}$ \\
\hline Female-to-male smoking & & -0.007 & -0.004 & -0.005 & -0.002 & -0.011 & -0.012 & -0.010 \\
\hline ratio & & $(0.008)$ & $(0.007)$ & $(0.008)$ & $(0.008)$ & $(0.009)$ & $(0.009)$ & $(0.009)$ \\
\hline $\begin{array}{l}\text { Female-to-male smoking } \\
\text { ratio*Female }\end{array}$ & & $\begin{array}{l}0.043^{* * *} \\
(0.010)\end{array}$ & $\begin{array}{l}0.044^{* * *} \\
(0.009)\end{array}$ & $\begin{array}{l}0.046^{* * *} \\
(0.012)\end{array}$ & $\begin{array}{l}0.042^{* * *} \\
(0.012)\end{array}$ & $\begin{array}{l}0.041^{* * *} \\
(0.013)\end{array}$ & $\begin{array}{l}0.041^{* * *} \\
(0.013)\end{array}$ & $\begin{array}{l}0.030^{* *} \\
(0.011)\end{array}$ \\
\hline Age & & & $\begin{array}{l}0.232^{*} \\
(0.118)\end{array}$ & $\begin{array}{l}0.198^{*} \\
(0.115)\end{array}$ & $\begin{array}{c}0.188 \\
(0.122)\end{array}$ & $\begin{array}{c}0.132 \\
(0.119)\end{array}$ & $\begin{array}{c}0.142 \\
(0.122)\end{array}$ & $\begin{array}{l}0.066 \\
(0.109)\end{array}$ \\
\hline Age squared & & & $\begin{array}{l}-0.005 \\
(0.004)\end{array}$ & $\begin{array}{l}-0.004 \\
(0.004)\end{array}$ & $\begin{array}{l}-0.005 \\
(0.004)\end{array}$ & $\begin{array}{l}-0.003 \\
(0.004)\end{array}$ & $\begin{array}{l}-0.003 \\
(0.004)\end{array}$ & $\begin{array}{l}-0.002 \\
(0.004)\end{array}$ \\
\hline Mother works & & & $\begin{array}{l}0.037^{* * *} \\
(0.013)\end{array}$ & $\begin{array}{l}0.045^{* * *} \\
(0.014)\end{array}$ & $\begin{array}{l}0.043^{* * *} \\
(0.013)\end{array}$ & $\begin{array}{l}0.037^{* * *} \\
(0.012)\end{array}$ & $\begin{array}{l}0.038^{* * *} \\
(0.012)\end{array}$ & $\begin{array}{l}0.034^{* * *} \\
(0.012)\end{array}$ \\
\hline Father works & & & $\begin{array}{c}-0.039^{* * *} \\
(0.014)\end{array}$ & $\begin{array}{l}-0.044^{* *} \\
(0.016)\end{array}$ & $\begin{array}{l}-0.032^{*} \\
(0.017)\end{array}$ & $\begin{array}{l}-0.012 \\
(0.017)\end{array}$ & $\begin{array}{l}-0.008 \\
(0.018)\end{array}$ & $\begin{array}{c}0.005 \\
(0.018)\end{array}$ \\
\hline Mother Educ. High & & & $\begin{array}{c}0.011 \\
(0.016)\end{array}$ & $\begin{array}{c}0.027 \\
(0.022)\end{array}$ & $\begin{array}{l}0.050^{* *} \\
(0.020)\end{array}$ & $\begin{array}{l}0.054^{* * *} \\
(0.019)\end{array}$ & $\begin{array}{l}0.054^{* * *} \\
(0.019)\end{array}$ & $\begin{array}{l}0.043^{* *} \\
(0.019)\end{array}$ \\
\hline Mother Educ. Medium & & & $\begin{array}{c}0.014 \\
(0.015)\end{array}$ & $\begin{array}{c}0.006 \\
(0.021)\end{array}$ & $\begin{array}{c}0.016 \\
(0.019)\end{array}$ & $\begin{array}{c}0.009 \\
(0.019)\end{array}$ & $\begin{array}{c}0.011 \\
(0.019)\end{array}$ & $\begin{array}{c}0.004 \\
(0.018)\end{array}$ \\
\hline Father Educ. High & & & $\begin{array}{c}-0.016 \\
(0.015)\end{array}$ & $\begin{array}{l}-0.020 \\
(0.022)\end{array}$ & $\begin{array}{l}-0.012 \\
(0.022)\end{array}$ & $\begin{array}{l}-0.004 \\
(0.020)\end{array}$ & $\begin{array}{l}-0.005 \\
(0.019)\end{array}$ & $\begin{array}{l}-0.009 \\
(0.021)\end{array}$ \\
\hline Father Educ. Medium & & & $\begin{array}{l}-0.005 \\
(0.011)\end{array}$ & $\begin{array}{c}0.002 \\
(0.014)\end{array}$ & $\begin{array}{c}0.002 \\
(0.013)\end{array}$ & $\begin{array}{l}-0.000 \\
(0.013)\end{array}$ & $\begin{array}{l}-0.000 \\
(0.012)\end{array}$ & $\begin{array}{c}0.002 \\
(0.012)\end{array}$ \\
\hline Age*Female & & & & $\begin{array}{c}0.073 \\
(0.185)\end{array}$ & $\begin{array}{c}0.138 \\
(0.180)\end{array}$ & $\begin{array}{c}0.134 \\
(0.167)\end{array}$ & $\begin{array}{c}0.107 \\
(0.168)\end{array}$ & $\begin{array}{c}0.055 \\
(0.159)\end{array}$ \\
\hline Age squared*Female & & & & $\begin{array}{l}-0.003 \\
(0.006)\end{array}$ & $\begin{array}{l}-0.005 \\
(0.006)\end{array}$ & $\begin{array}{l}-0.004 \\
(0.005)\end{array}$ & $\begin{array}{c}-0.004 \\
(0.005)\end{array}$ & $\begin{array}{l}-0.002 \\
(0.005)\end{array}$ \\
\hline Mother works*Female & & & & $\begin{array}{c}-0.015 \\
(0.021)\end{array}$ & $\begin{array}{l}-0.013 \\
(0.020)\end{array}$ & $\begin{array}{l}-0.013 \\
(0.021)\end{array}$ & $\begin{array}{c}-0.014 \\
(0.021)\end{array}$ & $\begin{array}{l}-0.020 \\
(0.021)\end{array}$ \\
\hline Father works*Female & & & & $\begin{array}{c}0.008 \\
(0.022)\end{array}$ & $\begin{array}{c}0.013 \\
(0.021)\end{array}$ & $\begin{array}{c}0.005 \\
(0.026)\end{array}$ & $\begin{array}{c}0.002 \\
(0.027)\end{array}$ & $\begin{array}{l}-0.014 \\
(0.026)\end{array}$ \\
\hline Mother Educ. High*Female & & & & $\begin{array}{l}-0.030 \\
(0.039)\end{array}$ & $\begin{array}{l}-0.038 \\
(0.034)\end{array}$ & $\begin{array}{l}-0.033 \\
(0.033)\end{array}$ & $\begin{array}{l}-0.035 \\
(0.034)\end{array}$ & $\begin{array}{l}-0.040 \\
(0.030)\end{array}$ \\
\hline Mother Educ. & & & & 0.018 & 0.015 & 0.017 & 0.014 & 0.019 \\
\hline Medium*Female & & & & $(0.032)$ & $(0.029)$ & $(0.030)$ & $(0.031)$ & $(0.027)$ \\
\hline Father Educ. High*Female & & & & $\begin{array}{c}0.012 \\
(0.034)\end{array}$ & $\begin{array}{c}0.017 \\
(0.032)\end{array}$ & $\begin{array}{c}0.021 \\
(0.029)\end{array}$ & $\begin{array}{c}0.022 \\
(0.030)\end{array}$ & $\begin{array}{c}0.031 \\
(0.026)\end{array}$ \\
\hline $\begin{array}{l}\text { Father Educ. } \\
\text { Medium*Female }\end{array}$ & & & & -0.013 & -0.005 & -0.002 & -0.002 & 0.003 \\
\hline Works & & & & & $0.107^{* * *}$ & $0.104^{* * *}$ & $0.097^{* * *}$ & $0.078^{* * *}$ \\
\hline
\end{tabular}




\begin{tabular}{|c|c|c|c|}
\hline (0.031) & (0.028) & (0.029) & (0.024) \\
\hline 0.004 & -0.003 & -0.007 & -0.017 \\
\hline (0.028) & $(0.027)$ & $(0.030)$ & $(0.028)$ \\
\hline $0.130^{* * *}$ & $0.112^{* * *}$ & $0.107^{* * *}$ & $0.104^{* * *}$ \\
\hline (0.018) & (0.019) & (0.019) & (0.018) \\
\hline 0.013 & 0.019 & 0.015 & 0.001 \\
\hline \multirow[t]{25}{*}{ (0.037) } & $(0.038)$ & $(0.038)$ & $(0.035)$ \\
\hline & $-0.083^{* * *}$ & $-0.079^{* * *}$ & $-0.063^{* * *}$ \\
\hline & $(0.022)$ & $(0.024)$ & $(0.021)$ \\
\hline & 0.021 & 0.022 & 0.031 \\
\hline & (0.033) & $(0.034)$ & (0.030) \\
\hline & $0.118^{* * *}$ & $0.107^{* * *}$ & $0.085^{* * *}$ \\
\hline & $(0.023)$ & $(0.022)$ & $(0.022)$ \\
\hline & 0.007 & 0.006 & 0.002 \\
\hline & $(0.029)$ & $(0.028)$ & $(0.028)$ \\
\hline & $0.075^{* * *}$ & $0.063^{* * *}$ & $0.048^{* *}$ \\
\hline & $(0.021)$ & $(0.021)$ & (0.019) \\
\hline & -0.015 & -0.021 & -0.019 \\
\hline & $(0.023)$ & $(0.024)$ & $(0.025)$ \\
\hline & & $0.164^{* * *}$ & $0.127^{* * *}$ \\
\hline & & (0.038) & $(0.037)$ \\
\hline & & 0.021 & 0.014 \\
\hline & & (0.039) & $(0.047)$ \\
\hline & & $0.034^{* *}$ & 0.014 \\
\hline & & $(0.015)$ & (0.016) \\
\hline & & 0.014 & -0.005 \\
\hline & & $(0.020)$ & (0.019) \\
\hline & & & $0.259^{* * *}$ \\
\hline & & & $(0.016)$ \\
\hline & & & $0.078^{* * *}$ \\
\hline & & & $(0.024)$ \\
\hline 0.112 & 0.136 & 0.148 & 0.253 \\
\hline 6,136 & 6,136 & 6,136 & 6,136 \\
\hline
\end{tabular}

\section{Grade Retention}

Grade Retention*Female

Lives with Mother and Father

Lives with Mother and

Father*Female

Cohabiting Mother Smokes

\section{Cohabiting Mother}

Smokes*Female

Cohabiting Father Smokes

Cohabiting Father

Smokes*Female

Cohabiting Siblings Smoke

Cohabiting Siblings

Smoke*Female

Students Smoke in School

Students Smoke in

School*Female

All/most/some Friends

Smoke

All/most/some Friends

Smoke*Female

$R^{2}$

Observations

$0.047 \quad 0.050$

$\begin{array}{ll}0.047 & 0.050 \\ 6,136 & 6,136\end{array}$

0.088

$6.136-0.088$

6,136

6,136

,136

year and province fixed effects. *** indicates significance at least the $1 \%$ level, ** at least the $5 \%$ level, * at least the $10 \%$ level. 